\title{
Multi-criteria performance optimization for operation of stratum ventilation under heating mode
}

\author{
Zhang, Sheng; Lin, Zhang; Ai, Zhengtao; Huan, Chao; Cheng, Yong; Wang, Fenghao
}

Published in:

Applied Energy

Link to article, DOI:

10.1016/j.apenergy.2019.01.248

Publication date:

2019

Document Version

Early version, also known as pre-print

Link back to DTU Orbit

\section{Citation (APA):}

Zhang, S., Lin, Z., Ai, Z., Huan, C., Cheng, Y., \& Wang, F. (2019). Multi-criteria performance optimization for operation of stratum ventilation under heating mode. Applied Energy, 239, 969-980.

https://doi.org/10.1016/j.apenergy.2019.01.248

\section{General rights}

Copyright and moral rights for the publications made accessible in the public portal are retained by the authors and/or other copyright owners and it is a condition of accessing publications that users recognise and abide by the legal requirements associated with these rights.

- Users may download and print one copy of any publication from the public portal for the purpose of private study or research.

- You may not further distribute the material or use it for any profit-making activity or commercial gain

- You may freely distribute the URL identifying the publication in the public portal 


\title{
Multi-criteria Performance Optimization for Operation of Stratum Ventilation under Heating Mode
}

Sheng Zhang ${ }^{1}$, Zhang Lin $^{2}$, Zhengtao $\mathrm{Ai}^{3}$, Chao Huan ${ }^{4}$, Yong Cheng ${ }^{5,6^{*}}$, Fenghao Wang $^{7 *}$

${ }^{1}$ Department of Architecture and Civil Engineering, City University of Hong Kong, Hong Kong, China

${ }^{2}$ Division of Building Science and Technology, City University of Hong Kong, Hong Kong, China

${ }^{3}$ International Centre for Indoor Environment and Energy, Department of Civil Engineering, Technical University of Denmark, Denmark

${ }^{4}$ School of Energy and Resource, Xi' an University of Science and Technology, Xi'an, China

${ }^{5}$ National Centre for International Research of Low-carbon and Green Buildings, Ministry of Science \& Technology, Chongqing University, Chongqing, China

${ }^{6}$ Key Laboratory of Three Gorges Reservoir Region’ s Eco-Environment, Ministry of Education, Chongqing University, Chongqing, China

${ }^{7}$ School of Human Settlements and Civil Engineering, Xi'an Jiaotong University, Xi'an, China

*Corresponding author. Tel.: +86 2365120771; fax: +86 2365126160; E-mail: yongcheng6@cqu.edu.cn

*Corresponding author. E-mail: fhwang@mail.xjtu.edu.cn

\begin{abstract}
Stratum ventilation with proper operation can energy-efficiently provide thermal comfort and good quality of inhaled air. Previous studies were mainly focused on stratum ventilation for cooling, with little attention on stratum ventilation for heating. Proper operation of stratum ventilation for heating is more complicated, with multiple ventilation operation parameters (i.e., the supply vane angle, supply airflow rate, and supply air temperature) non-linearly affecting multiple mutually conflicting criteria of the ventilation performance (i.e., thermal comfort, air quality, and energy efficiency). In this study, the operation of stratum ventilation for heating is optimized by using a
\end{abstract}


multi-criteria decision-making technology, namely a technique of order preference by similarity to ideal solution (TOPSIS). An experiment on stratum ventilation for heating a typical office is conducted. Based on experimentally validated Computational Fluid Dynamics (CFD) simulations, response surface models of the ventilation performance are developed to promote the computational efficiency of the TOPSIS optimization. The operation optimization on the ventilation parameters significantly improves the ventilation performance, with an average reduction of $16.3 \%$ and $29.5 \%$ in the Predicted Percentage Dissatisfied and the local mean age of air, respectively, and an average increase of $7.0 \%$ in the energy utilization coefficient. When the outdoor weather varies, the optimal supply air temperature varies most frequently with the greatest variation range, followed by the optimal supply vane angle, and the optimal supply airflow rate. With the ability to modulate the optimal supply air temperature as a response to outdoor-weather variations, the constant-air-volume system is preferable to the variable-air-volume system.

Keywords: Stratum ventilation; Heating; Operation optimization; TOPSIS; Response surface model

\section{Nomenclature}

$\beta_{o}, \beta_{i}, \quad$ coefficients of the response surface

$\beta_{i i}, \beta_{i j}$ model

$y \quad$ response parameter

$D_{i}^{+} / D_{i}^{-} \quad$ separation from positive/negative

$f_{1}, f_{2}$ ideal solution

$y_{i j} / y_{i j}^{\prime} \quad$ original/normalized value

$f_{3}, f_{4}$

response surface model

$i$ $i^{\text {th }}$ alternative of operation/case weighted normalized value

$j / k \quad j^{\text {th }} / k^{t h}$ criterion $z_{j}^{+} / z_{j}^{-}$ positive/negative ideal

$J_{1} / J_{2} \quad$ benefit/cost criterion $\sigma_{j}$ solution

$M_{j} \quad$ amount of information

\section{Abbreviations}

$n \quad$ number of design parameters/criteria

$\mathrm{ACH}$ air changes per hour

$N \quad$ number of cases

CAV constant-air-volume

CFD

pre $_{\mathrm{i}} \quad$ prediction by response surface model

CRITIC Computational Fluid $R^{2} \quad$ coefficient of determination

DO Dynamics criteria importance through inter-criteria correlation discrete ordinates 
Volume 239, 1 April 2019, Pages 969-98

\begin{tabular}{|c|c|c|c|}
\hline $\operatorname{sim}_{\mathrm{i}}$ & CFD simulations & EUC & energy utilization coefficient \\
\hline$T_{\mathrm{e}}$ & exit air temperature $\left({ }^{\circ} \mathrm{C}\right)$ & LMAA & local mean age of air \\
\hline$T_{\mathrm{r}}$ & room air temperature $\left({ }^{\circ} \mathrm{C}\right)$ & MAE & mean absolute error \\
\hline$T_{\mathrm{s}}$ & supply air temperature $\left({ }^{\circ} \mathrm{C}\right)$ & NIS & negative ideal solution \\
\hline$T_{\mathrm{w}}$ & $\begin{array}{l}\text { inside surface temperature of the } \\
\text { exterior envelope }\left({ }^{\circ} \mathrm{C}\right)\end{array}$ & PIS & positive ideal solution \\
\hline$\Delta T$ & $\begin{array}{l}\text { vertical air temperature difference } \\
\text { between head and ankle levels }\left({ }^{\circ} \mathrm{C}\right)\end{array}$ & PMV & Predicted Mean Vote \\
\hline$V_{\mathrm{s}}$ & supply airflow rate $\left(\mathrm{m}^{3} / \mathrm{s}\right)$ & PPD & $\begin{array}{l}\text { Predicted Percentage } \\
\text { Dissatisfied }\end{array}$ \\
\hline$V A_{\mathrm{s}}$ & supply vane angle $\left(^{\circ}\right)$ & $\mathrm{RI}_{\mathrm{i}}$ & rank index \\
\hline$w_{j}$ & weight factor & $\mathrm{RSM}$ & $\begin{array}{l}\text { response surface model/ } \\
\text { methodology }\end{array}$ \\
\hline $\bar{x}$ & $\begin{array}{l}\text { normalized value of design } \\
\text { parameter }\end{array}$ & TOPSIS & $\begin{array}{l}\text { technique of order preference } \\
\text { by similarity to ideal solution }\end{array}$ \\
\hline$x_{i} / x_{j}$ & $\begin{array}{l}\text { original value of } i^{t h} / j^{t h} \text { design } \\
\text { parameters }\end{array}$ & VAV & variable-air-volume \\
\hline $\begin{array}{l}x_{\max } \\
/ x_{\min }\end{array}$ & $\begin{array}{l}\text { maximal/minimal original value of } \\
\text { design parameter }\end{array}$ & & \\
\hline
\end{tabular}

\section{Introduction}

Buildings consume approximately $40 \%$ of the primary energy worldwide $[1,2]$. Because heating, ventilation, and air conditioning (HVAC) systems mainly account for the energy consumption in buildings, improving their energy efficiency is essential for energy saving in buildings. To achieve this, one of the most effective manners is through the improvement of the performance of air distributions (e.g., mixing ventilation) [2]. Air distributions are responsible for the indoor thermal comfort and air quality, which significantly affect the health and productivity of occupants [3]. There is a trend to shift mixing ventilation with a uniform thermal environment to air distributions focusing on the occupied zone (e.g., stratum ventilation), in order to save energy used for conditioning the upper zone without occupants whilst maintaining satisfactory thermal comfort and air quality in the occupied zone [3, 4]. Stratum ventilation is a novel air distribution, which is proposed for application to small-to-medium-sized spaces [5, 6]. Compared with mixing ventilation, stratum ventilation can save energy annually by at least $44.37 \%$ [7]. Moreover, the elevated thermally neutral temperature of stratum ventilation (approximately $27^{\circ} \mathrm{C}$ ) is 


\author{
Applied Energy \\ Volume 239, 1 April 2019, Pages 969-98
}

particularly beneficial for the applications of solar cooling systems $[8,9]$.

To achieve a good operation performance of stratum ventilation, the ventilation parameters should be properly controlled. Objective measurements and subjective surveys showed that with a supply airflow rate of 10 air changes per hour (ACH), increasing the supply air temperature from 18.5 to $21.5^{\circ} \mathrm{C}$ caused the slightly cool thermal environment to become slightly warm, and reduced draft rate from $37 \%$ to $2 \%$ [10]. Huan et al. [11] experimentally revealed that the supply airflow rate and the supply air temperature interactively affected the energy efficiency. For the improvement of thermal comfort, Shao et al. [12] and Zhang et al. [13] proposed that differentiated thermal preferences be considered. Cheng et al. [14] and Zhang et al. $[15,16]$ proposed optimization methods for the room air temperature and the fresh outdoor air ratio to maximize energy efficiency, while achieving thermal comfort and good air quality. The room air temperature can be predicted by the nodal model, in which the supply airflow rate, as well as the supply air temperature and cooling load, are used as inputs [17], whereas the cooling load can be predicted by the equivalent room air temperature method [18].

However, previous studies have mainly been focused on stratum ventilation for cooling, with little attention on stratum ventilation for heating [19]. In addition, stratum ventilation has potential for application to heating because of its high supply air velocity and its layout of return outlet(s), which makes it capable of avoiding short-circuiting $[19,20]$. However, owing to the effects of upward thermal buoyancy, the airflow pattern of stratum ventilation for heating is distinct from that of stratum ventilation for cooling [19]. The proper operation of stratum ventilation for heating is more complicated than that for cooling. Different from stratum ventilation for cooling, which horizontally supplies cooled air to the head level of the occupants [21, 22], stratum ventilation for heating requires additional control on the supply vane angle of the heated air. If the heated air is also supplied horizontally (i.e., supply vane angle $=$ $0^{\circ}$ in Figure 1), it will flow upward into the unoccupied upper zone owing to the upward thermal buoyancy, thus resulting in poor ventilation performance for the occupied zone [19]. Hence, the findings in stratum ventilation for cooling are not applicable to stratum ventilation for heating $[14,15]$; the optimization of the stratum ventilation for heating is required to improve the operation performance. 


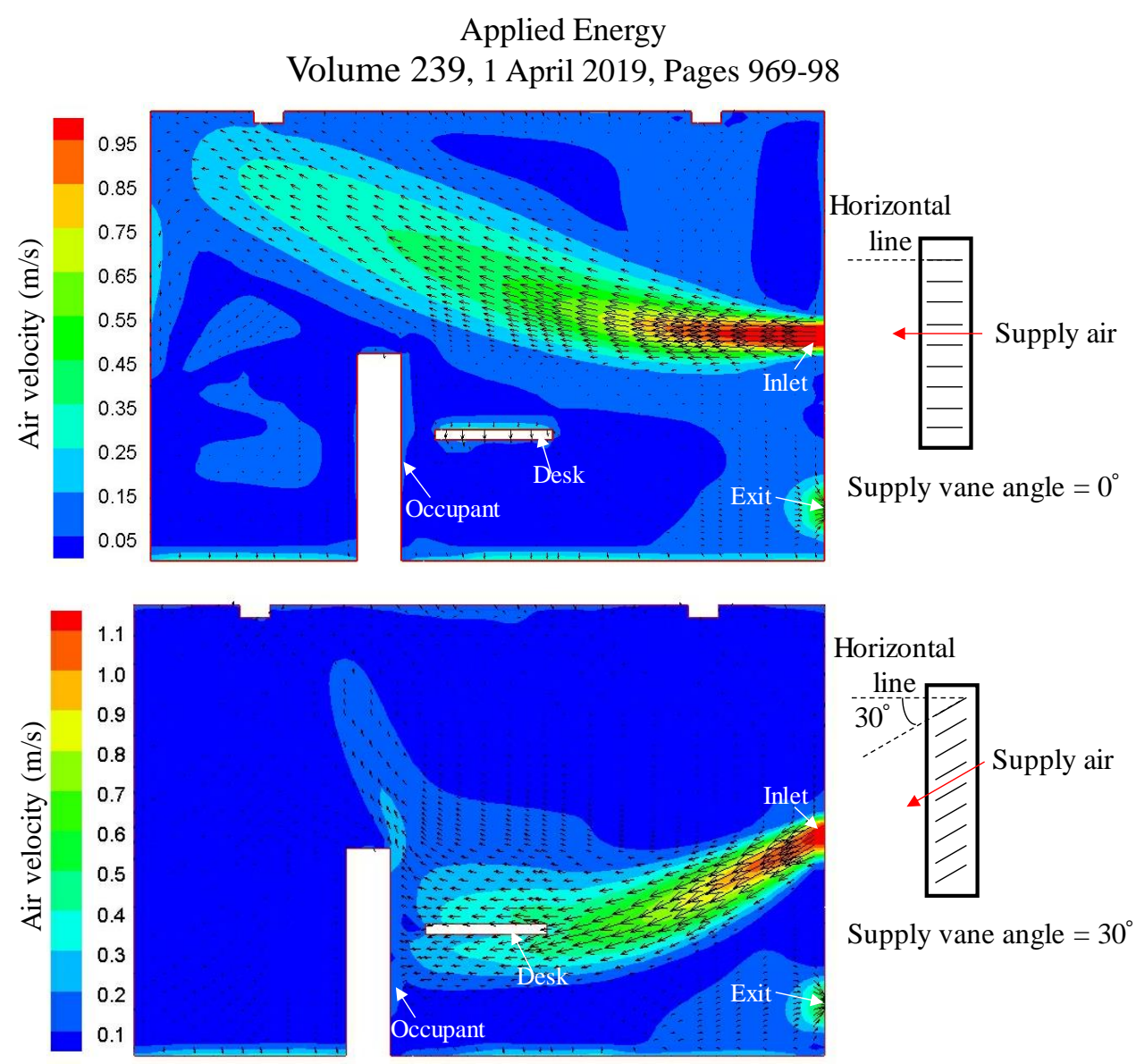

Fig.1. Demonstration of definition of supply vane angle and effects of supply vane angle on supply air trajectory.

The operation optimization of stratum ventilation for heating is a multi-criteria decision-making problem. It has been confirmed that the multiple ventilation parameters (i.e., the supply vane angle, the supply airflow rate, and the supply air temperature) of stratum ventilation for heating non-linearly determine the mutually conflicting criteria of thermal comfort, air quality, and energy efficiency [19]. For instance, increasing the supply vane angle could mitigate the local thermal discomfort; however, it could deteriorate the air quality [19]. The technique of order preference by similarity to ideal solution (TOPSIS) is one of the most well-known multi-criteria decision-making technologies [23]. TOPSIS determines the optimal alternative that simultaneously has the shortest distance from the positive ideal solution and the longest distance from the negative ideal solution [24]. The positive ideal solution denotes the ideal solution that maximizes all benefit criteria and minimizes all cost criteria, and the negative ideal solution denotes the ideal solution that minimizes all benefit criteria and maximizes all cost criteria [25]. Thus, TOPSIS could make a reasonable trade-off among mutually conflicting criteria [23]. 


\section{Applied Energy \\ Volume 239, 1 April 2019, Pages 969-98}

In this study, the operation of stratum ventilation for heating is optimized by using TOPSIS. The operation optimization is based on Computational Fluid Dynamics (CFD) simulations, which are experimentally validated. Because TOPSIS requires the evaluation of the ventilation performance of all possible operations (i.e., combinations of different possible values of the three ventilation parameters) for different outdoor weather conditions, the computational cost of CFD simulations would be fairly expensive. To improve the computational efficiency of the optimization, response surface models of ventilation performance are first developed and are then used to evaluate the ventilation performance of all possible operations for the TOPSIS optimization. The response surface methodology (RSM) is a powerful surrogate modeling technology for the built environment [26-28]. It is the first time that the RSM-based TOPSIS optimization is proposed for the efficient and effective improvement of the quality of built environments.

The main contributions of this study are (1) the optimization of the operation performance of stratum ventilation for heating, (2) the comparison of the optimized operation performance of three different systems (i.e., the constant-air-volume system, the variable-air-volume system, and the system with variable supply airflow rate and supply air temperature) with the purpose of making recommendations for the design of stratum ventilation for heating, and (3) the use of RSM for the improvement of the computational efficiency of the TOPSIS optimization of the indoor thermal environment.

\section{Methodology}

\subsection{Evaluation indices of ventilation performance}

Four criteria of ventilation performance are included: the Predicted Mean Vote/Predicted Percentage Dissatisfied (PMV/PPD) for the overall thermal comfort, the vertical air temperature difference between head and ankle levels $(\Delta T)$ for local thermal comfort, the local mean age of air (LMAA) for indoor air quality, and the energy utilization coefficient (EUC) for energy efficiency. The detailed calculation of the PMV can refer to ASHRAE 55 [29]. The PPD is calculated from the PMV (Equation 1) [30]. The LMAA is defined as the average lifetime of air at a particular location and indicates the "freshness" of the air [22]. The EUC is calculated via 
Equation 2 [16, 17]. The PPD, the LMAA, and the EUC are the optimization objectives. Smaller values of the PPD and the LMAA and higher values of EUC are more preferred $[16,19,29] . \Delta T$ is an optimization constraint that is limited to less than $3^{\circ} \mathrm{C}$ [30]. It is noted that the percentage of dissatisfied people owing to the draft (PD) is also an important aspect regarding the local thermal comfort; however, it has been excluded in this study. The PD of stratum ventilation for heating is less than $15 \%$ in general [19] indicating a low draft risk [30].

$$
\begin{gathered}
P P D=100-95 \exp \left(-0.03353 P M V^{4}-0.2179 P M V^{2}\right) \\
E U C=\frac{T_{\mathrm{s}}-T_{\mathrm{e}}}{T_{\mathrm{s}}-T_{\mathrm{r}}}
\end{gathered}
$$

$T_{\mathrm{e}}, T_{\mathrm{r}}$, and $T_{\mathrm{s}}$ are the temperatures of the exit air, the air in the occupied zone, and the supply air, respectively $\left({ }^{\circ} \mathrm{C}\right)$; the definition of the occupied zone can be found in Awbi [31].

\subsection{Experiment}

The experiment is conducted in a test chamber at the Xi' an Jiaotong University during winter. This chamber resembles a typical office with dimensions of 3.9 m (length) $\times$ $2.9 \mathrm{~m}$ (width) $\times 2.6 \mathrm{~m}$ (height) (Figure 2) and uses stratum ventilation. A rectangular grille supply diffuser $(0.2 \mathrm{~m} \times 0.17 \mathrm{~m})$ is located at a height of $1.3 \mathrm{~m}$ on the right wall and a perforated exhaust $(0.6 \mathrm{~m} \times 0.6 \mathrm{~m})$ is installed on the ceiling. The occupant is simulated by a rectangular thermal manikin, with dimensions of $0.4 \mathrm{~m}$ (length) $\times 0.25$ $\mathrm{m}$ (width) $\times 1.2 \mathrm{~m}$ (height), which is heated by three $25 \mathrm{~W}$ light bulbs [32]. A box (0.4 $\mathrm{m} \times 0.4 \mathrm{~m} \times 0.4 \mathrm{~m}$ ) with three $60 \mathrm{~W}$ light bulbs is placed on the desk to simulate a computer [32]. Two ceiling lamps, each with an electrical power of $72 \mathrm{~W}$ are used for illumination. 

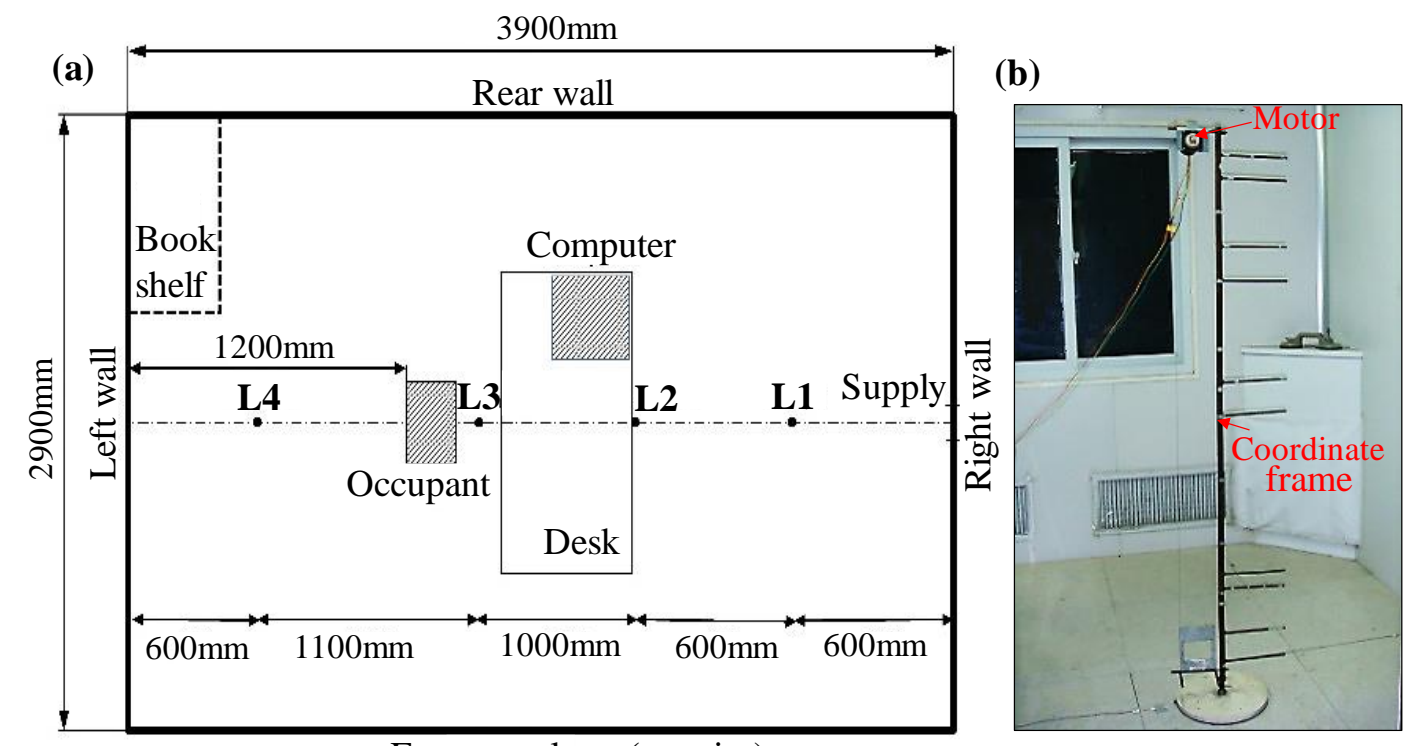

Front envelope (exterior)

Note: L1- L4 are sampling lines.

Fig.2. (a) Setup of test chamber; (b) automatic elevation system for adjustment of positions of sensors.

The measurements are collected under a steady-state condition. The supply vane angle, the supply air velocity, and the supply air temperature are $30^{\circ}, 1.6 \mathrm{~m} / \mathrm{s}$, and $23^{\circ} \mathrm{C}$, respectively. The indoor air velocity and temperature are measured along four sampling lines (i.e., L1 - L4) at nine different heights above the floor using SWEMA 03 omnidirectional anemometers (Figure 2(a)), namely at $0.3 \mathrm{~m}, 0.5 \mathrm{~m}, 0.7 \mathrm{~m}, 0.9 \mathrm{~m}$, $1.1 \mathrm{~m}, 1.3 \mathrm{~m}, 1.5 \mathrm{~m}, 1.7 \mathrm{~m}$, and $2.1 \mathrm{~m}$ above the floor. For the air velocity, the measurement range is $0.05-3 \mathrm{~m} / \mathrm{s}$, and the measurement error is $\pm 0.03 \mathrm{~m} / \mathrm{s}$ for 0.05 $1.00 \mathrm{~m} / \mathrm{s}$ and $\pm 3 \%$ for $1.00-3.00 \mathrm{~m} / \mathrm{s}$. For the air temperature, the measurement range is $10-34^{\circ} \mathrm{C}$, and the measurement error is $\pm 0.3^{\circ} \mathrm{C}$. To avoid the disturbance of the indoor airflow caused by the laboratory staff, the anemometers are automatically elevated from one height on the coordinate frame to another using an elevation system with a motor to change the positions of sensors (Figure 2(b)). For each height, the measurement lasts for $15 \mathrm{~min}$ and the sampling frequency is $10 \mathrm{~Hz}$. A copper-copper nickel thermocouple system is used for the measurement of the wall surface temperatures, with a measurement error of $\pm 0.4^{\circ} \mathrm{C}$. 


\subsection{CFD simulation}

Experimental measurements and CFD simulations are the two main research methods employed in the study of the indoor environment with various air distributions. Although experimental measurements can provide the most realistic data, they are expensive and time-consuming. With the rapid development of computational capabilities, CFD simulations of lower cost are widely used for the prediction of indoor air flow, indoor air temperature, thermal comfort, indoor air quality, etc. [12, 19, 33, 34]. Experimental measurements can be collected to validate the reliability of CFD simulations. The experimentally validated CFD simulations are used to produce data for the development and validation of the response surface models. This is a common practice in the field of built environment [26-28].

In order to ensure the high quality of the CFD simulations, this study follows a standard procedure of verification and validation of CFD simulations of indoor thermal environment [35]. A physical model similar to the one used in the experimental measurements is adopted in the CFD simulations (Figure 3(a)). However, there are two differences (Figures 2 and 3(a)). One is that a bookshelf is added to the CFD model to more realistically resemble a typical office environment. The other is that the indoor air is exhausted by an outlet located at a lower level on the same wall as the one where the supply diffuser is located because this outlet layout can provide better thermal comfort and air quality [19]. Airpak 3.0.16 [36] is employed to construct the physical model and to generate the mesh (Figure 3(b)). A commercial CFD code [37] is used for the calculation of the thermal environment inside the office. The air flows in the room are assumed to be steady-state, incompressible, and turbulent. According to previous studies [38, 39], the standard $\mathrm{k}-\varepsilon$ model is used for the modeling of the turbulent flow. Compared with the RNG k-E model and the SST $\mathrm{k}-\omega$ model, the standard $\mathrm{k}-\varepsilon$ model predicts the air velocity and the temperature distributions of stratum ventilation more reliably $[19,40]$. The standard wall function is employed to model the turbulent flow in the near-wall region [37]. To ensure that 
Volume 239, 1 April 2019, Pages 969-98

the first grid point is located in the logarithmic region, the non-dimensional wall distance, $y^{+}$, should be larger than 11.225 [37]. In this study, $y^{+}$is controlled within the range of 16-188. The discrete ordinates (DO) model is used for the computation of the radiative heat exchange among the surfaces of the office. The buoyancy effect is considered using the Boussinesq model [37].
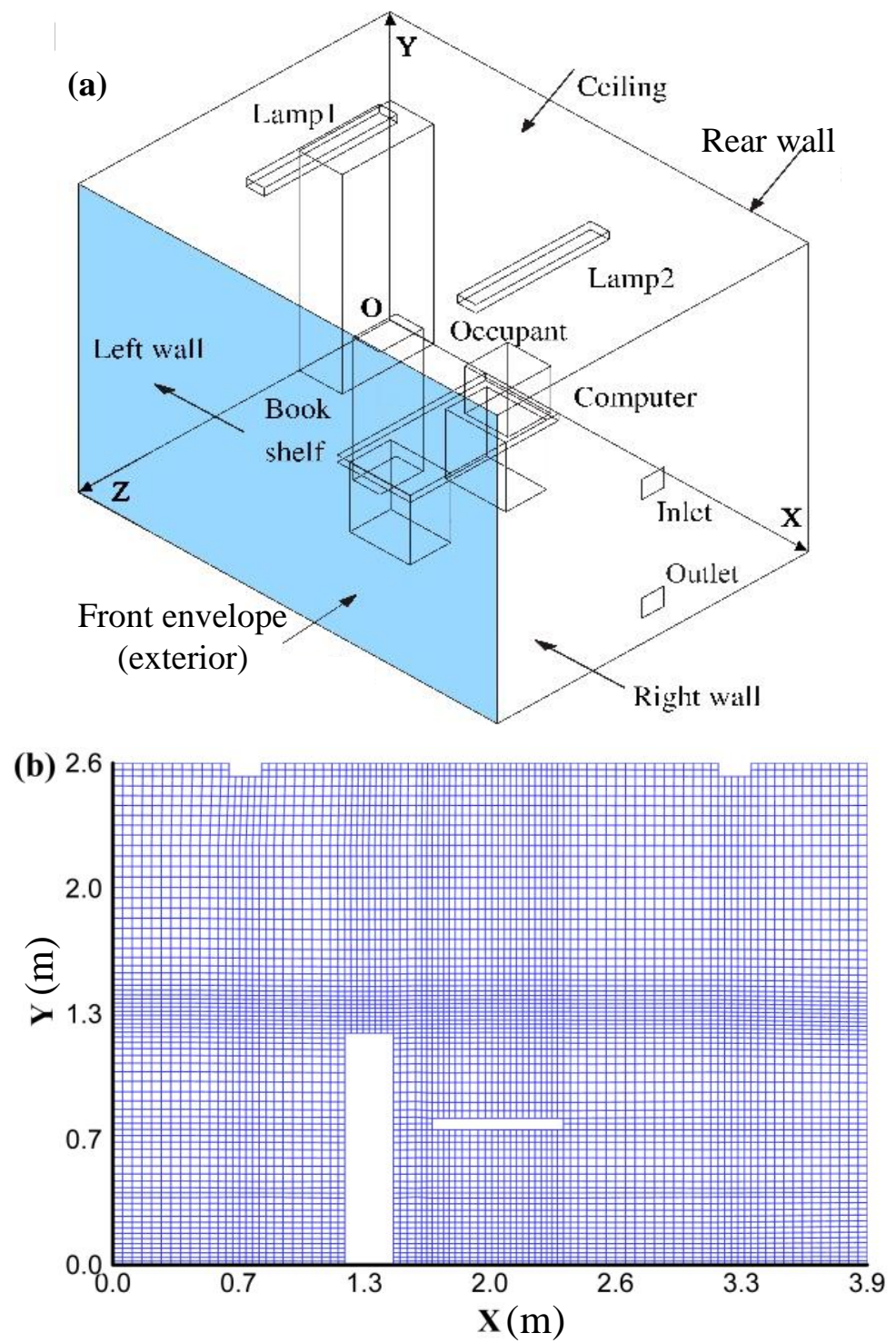

Fig.3. CFD model: (a) General configuration of a typical stratum-ventilated office; (b) mesh of computational domain $(\mathrm{Z}=1.45 \mathrm{~m})$.

To ensure that the predicted results would be independent of the grid number, grid sensitivity tests are conducted. The office is discretized using 270,946 (coarse), 532,572 (moderate), and 993,551 (fine) hexahedral grids. In Figure 4, the predicted 
velocities and temperatures of the three types of grids along Sampling line 1 ( $X=3.3$ $\mathrm{m}, \mathrm{Z}=1.45 \mathrm{~m}$ ) of the benchmark case (i.e., Case 7 in Table 1) are compared. The velocities and temperatures predicted using the moderate grid are close to those predicted using the fine grid, whereas the air temperatures predicted using the coarse grid largely deviate from those predicted using the fine grid. Thus, considering the prediction accuracy and the computational cost, the moderate grid is adopted.
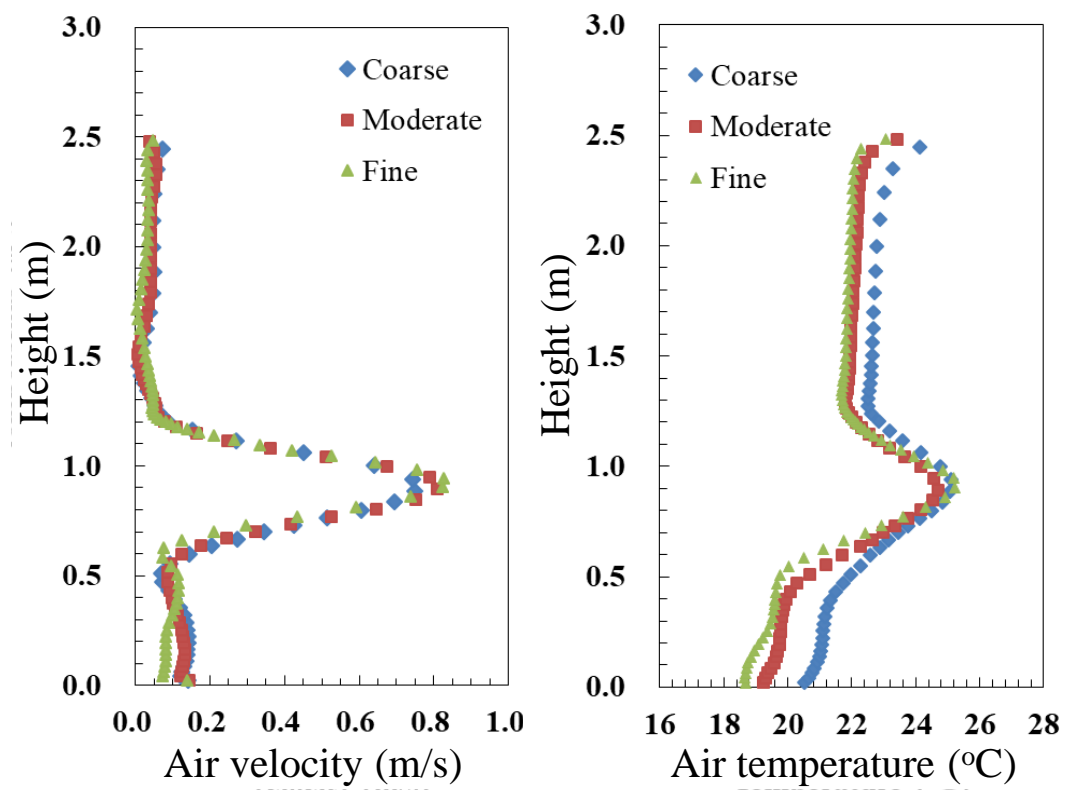

Fig.4. Grid-independent tests.

The inlet and outlet of the computational domain are specified as the velocity inlet boundary and outflow boundary, respectively. Based on the experiment, heat sources including the occupant, the computer, and the ceiling lamps are set as the constant heat-flux boundary condition (Section 2.2). The front envelope is set as the constant wall temperature boundary condition to evaluate the effects of the outdoor weather conditions (Figure 3(a)) [41, 42]. However, the remaining walls, the floor, and the ceiling are assumed to be adiabatic. The pressure-velocity coupling method is the SIMPLE algorithm. The pressure is discretized with a standard scheme, and the convective term is calculated using the second-order upwind scheme. The solutions are considered to converge when the scaled residuals are less than $10^{-6}$ for the energy and the LMAA, and $10^{-4}$ for other variables. Based on the predicted fields of air velocity and temperature, the PMV and the PPD are calculated via the user-defined 
functions (UDF) implemented in FLUENT. The LMAA is determined by solving a transport scalar equation [43].

\subsection{Response surface modeling}

Based on CFD simulations of several specific operation cases, in this study, the RSM is used to identify the relationship (i.e., the response surface model) between a design response and a set of design parameters (Equation 3) [44, 45]. The design responses refer to the four criteria of ventilation performance (Section 2.1). The design parameters include the three ventilation parameters (i.e., the supply vane angle, the supply airflow rate, and the supply air temperature), as well as the inside surface temperature of the exterior envelope. The inside surface temperature of the exterior envelope indicates the outdoor weather conditions [41, 42]. The coefficients of the response surface model (i.e., Equation 3) can be determined by the least-square method, and the backward elimination procedure is used to enhance the data fit of the response surface model as follows. First, the response surface model is quantified via the least-square method. Second, the $p$ values of the model terms (e.g., $x_{i} x_{j}$ in Equation 3) are calculated via Analysis of Variance (ANOVA) test. The model terms with $p$ values higher than 0.05 are considered statistically insignificant and are removed from the response surface model. The Design-Expert software [46] can make the development of the response surface model user-friendly. More details on the development of the response surface model can be found in Reference [26].

$$
y=\beta_{o}+\sum_{i=1}^{n} \beta_{i} x_{i}+\sum_{i=1}^{n} \beta_{i i} x_{i}^{2}+\sum_{i=1}^{n} \sum_{j>i}^{n} \beta_{i j} x_{i} x_{j}
$$

where $y$ is the response parameter; $\beta_{o}, \beta_{i}, \beta_{i i}$, and $\beta_{i j}$ are coefficients; $x_{i}$ and $x_{j}$ are the $i^{\text {th }}$ and $j^{\text {th }}$ design parameters, respectively; in total, there are $n$ different design parameters.

The specific operation cases are determined via the Box-Behnken design, which is a Design of Experiment method. Although other Design of Experiment methods are also available, e.g., full factorial design and central composite design [47], the BoxBehnken design is popularly used [26, 48]. Because the Box-Behnken design can reduce the required specific operation cases while ensuring a satisfactory accuracy of the response surface models. A more detailed introduction to the Box-Behnken design 


\section{Applied Energy}

Volume 239, 1 April 2019, Pages 969-98

can be found in Shen et al. [26]. The determined 25 specific operation cases are listed in Table 1. In this study, the supply vane angle, the supply airflow rate, and the supply air temperature range from $0^{\circ}$ to $70^{\circ}, 0.02$ to $0.04 \mathrm{~m}^{3} / \mathrm{s}$, and 24 to $28^{\circ} \mathrm{C}$, respectively, to create a thermal environment from slightly cool to slightly warm which is commonly encountered in practice $[10,16]$. The inside surface temperature of the exterior envelope ranges from 10 to $17^{\circ} \mathrm{C}$, indicating a wide variation in the outdoor weather conditions for the heating mode [40, 41].

Table 1. Cases determined by Box-Behnken design and associated ventilation performance from CFD simulations.

\begin{tabular}{|c|c|c|c|c|c|c|c|c|}
\hline \multirow{3}{*}{ Cases } & \multicolumn{3}{|c|}{ Design parameters } & \multicolumn{4}{c|}{ Design responses } \\
\cline { 2 - 9 } & $\begin{array}{c}V A_{\mathrm{s}} \\
\left({ }^{\circ}\right)\end{array}$ & $\begin{array}{c}V_{\mathrm{s}} \\
\left(\mathrm{m}^{3} / \mathrm{s}\right)\end{array}$ & $\begin{array}{c}T_{\mathrm{s}} \\
\left({ }^{\circ} \mathrm{C}\right)\end{array}$ & $\begin{array}{c}T_{\mathrm{w}} \\
\left({ }^{\circ} \mathrm{C}\right)\end{array}$ & $\begin{array}{c}\text { PMV } \\
(-)\end{array}$ & $\begin{array}{c}\Delta T \\
\left({ }^{\circ} \mathrm{C}\right)\end{array}$ & $\begin{array}{c}\text { LMAA } \\
(\mathrm{s})\end{array}$ & $\begin{array}{c}\text { EUC } \\
(-)\end{array}$ \\
\hline 1 & 35 & 0.02 & 26 & 10 & -0.71 & 2.36 & 1313 & 1.10 \\
\hline 2 & 0 & 0.03 & 26 & 10 & -0.49 & 2.48 & 960 & 1.14 \\
\hline 3 & 35 & 0.03 & 24 & 17 & 0.15 & 0.62 & 875 & 1.78 \\
\hline 4 & 70 & 0.04 & 26 & 13.5 & -0.17 & 0.49 & 887 & 0.78 \\
\hline 5 & 0 & 0.03 & 24 & 13.5 & -0.1 & 2.07 & 887 & 1.21 \\
\hline 6 & 0 & 0.04 & 26 & 13.5 & 0.2 & 2.54 & 642 & 1.17 \\
\hline 7 & 35 & 0.03 & 26 & 13.5 & 0.01 & 1.84 & 845 & 1.24 \\
\hline 8 & 70 & 0.03 & 28 & 13.5 & -0.08 & 0.77 & 1178 & 0.78 \\
\hline 9 & 70 & 0.02 & 26 & 13.5 & -0.32 & 0.88 & 2005 & 0.75 \\
\hline 10 & 70 & 0.03 & 26 & 17 & 0.26 & 0.68 & 1217 & 0.77 \\
\hline 11 & 35 & 0.04 & 26 & 17 & 0.43 & 0.94 & 662 & 1.48 \\
\hline 12 & 70 & 0.03 & 24 & 13.5 & -0.35 & 0.63 & 1194 & 0.78 \\
\hline 13 & 35 & 0.02 & 28 & 13.5 & -0.04 & 2.24 & 1389 & 1.12 \\
\hline 14 & 35 & 0.04 & 26 & 10 & -0.39 & 1.9 & 643 & 1.14 \\
\hline 15 & 35 & 0.02 & 24 & 13.5 & -0.25 & 1.85 & 1340 & 1.20 \\
\hline 16 & 35 & 0.03 & 28 & 17 & 0.59 & 1.43 & 857 & 1.26 \\
\hline 17 & 0 & 0.03 & 26 & 17 & 0.48 & 1.77 & 875 & 1.27 \\
\hline 18 & 35 & 0.04 & 28 & 13.5 & 0.21 & 1.59 & 653 & 1.19 \\
\hline 19 & 35 & 0.03 & 24 & 10 & -0.59 & 2.22 & 854 & 1.21 \\
\hline 20 & 35 & 0.03 & 28 & 10 & -0.25 & 3.06 & 934 & 1.15 \\
\hline 21 & 70 & 0.03 & 26 & 10 & -0.75 & 0.77 & 1193 & 0.79 \\
\hline 22 & 35 & 0.02 & 26 & 17 & 0.38 & 1.58 & 1297 & 1.26 \\
\hline 23 & 0 & 0.02 & 26 & 13.5 & -0.22 & 1.79 & 1343 & 1.12 \\
\hline 25 & 0 & 0.03 & 28 & 13.5 & 0.15 & 2.35 & 913 & 1.14 \\
\hline & 35 & 0.04 & 24 & 13.5 & -0.15 & 1.1 & 677 & 1.40 \\
\hline
\end{tabular}




\subsection{RSM-based TOPSIS optimization}

The RSM-based TOPSIS optimization can be divided into seven steps (Figures 5 and 6). Step 1 is to build a decision matrix which presents the results of each criterion of the ventilation performance for each possible alternative of operation. An alternative of operation is a combination of the supply vane angle, the supply airflow rate, and the supply air temperature. The criteria (i.e., the PPD, the LMAA, and the EUC) of the ventilation performance are calculated via the developed response surface models. Step 2 is to normalize the decision matrix (Equation 4). Step 3 is to weigh the normalized decision matrix (Equation 5). Step 4 is to identify the positive ideal solution and the negative ideal solution (Equations 6 and 7). Step 5 is to calculate the separation from the positive ideal solution and the negative ideal solution for each alternative of operation (Equations 8 and 9). Step 6 is to calculate the rank index of each alternative of operation (Equation 10). The rank index is regarded as the overall score. The overall score varies from zero to one, and an alternative of operation with a greater overall score is more preferred. During this step, the vertical air temperature difference $(\Delta \mathrm{T})$ between head and ankle levels is constrained to be less than $3^{\circ} \mathrm{C}[30]$. More specifically, the overall score of the alternative of operation with a vertical air temperature difference of $(\Delta \mathrm{T}) \geqslant 3^{\circ} \mathrm{C}$ is assigned to be zero. The vertical air temperature difference $(\Delta T)$ is calculated via its response surface model. Step 7 is to rank the alternatives of operation in a manner that the alternative of operation with a greater overall score is derived the former. The alternative of operation in the first place is selected as the optimal operation.

$$
y_{i j}^{\prime}=\frac{y_{i j}}{\sum_{i=1}^{m} y_{i j}}
$$

where $y_{i j}$ and $y_{i j}^{\prime}$ are original value and normalized value of the $j^{\text {th }}$ criterion for the $i^{\text {th }}$ alternative of operation, respectively.

$$
z_{i j}=w_{j} y_{i j}^{\prime}
$$

where $w_{j}$ is the weight factor of the $j^{\text {th }}$ criterion; $z_{i j}$ is the weighted normalized value of the $j^{\text {th }}$ criterion for the $i^{\text {th }}$ alternative of operation.

$$
\begin{aligned}
& P I S=\left\{z_{1}^{+}, \ldots, z_{j}^{+}, \ldots, z_{n}^{+}\right\}=\left\{\underset{\forall i}{\operatorname{Max}} z_{i j}\left|j \in J_{1}, \underset{\forall i}{\operatorname{Min}} z_{i j}\right| j \in J_{2}\right\} \\
& N I S=\left\{z_{1}^{-}, \ldots, z_{j}^{-}, \ldots, z_{n}^{-}\right\}=\left\{\operatorname{Min}_{\forall i} z_{i j}\left|j \in J_{1}, \underset{\forall i}{\operatorname{Max}} z_{i j}\right| j \in J_{2}\right\}
\end{aligned}
$$

where PIS and NIS are the positive ideal solution and the negative ideal solution, 
respectively; $z_{j}^{+}$and $z_{j}^{-}$are PIS and NIS of the $j^{\text {th }}$ criterion, respectively; $J_{1}$ is the benefit criterion, i.e., the EUC; and $J_{2}$ is the cost criterion, i.e., the PPD and the LMAA.

$$
\begin{aligned}
& D_{i}^{+}=\sqrt{\sum_{j=1}^{n}\left(z_{i j}-z_{j}^{+}\right)^{2}} \\
& D_{i}^{-}=\sqrt{\sum_{j=1}^{n}\left(z_{i j}-z_{j}^{-}\right)^{2}}
\end{aligned}
$$

where $D_{i}^{+}$and $D_{i}^{-}$are separations from the positive ideal solution and the negative ideal solution of the $i^{\text {th }}$ alternative of operation, respectively.

$$
R I_{i}= \begin{cases}\frac{D_{i}^{-}}{D_{i}^{+}+D_{i}^{-}} & \Delta \mathrm{T}<3^{\circ} \mathrm{C} \\ 0 & \Delta \mathrm{T} \geq 3^{\circ} \mathrm{C}\end{cases}
$$

where $R I_{i}$ is the rank index (i.e., the overall score) of the $i^{\text {th }}$ alternative of operation.

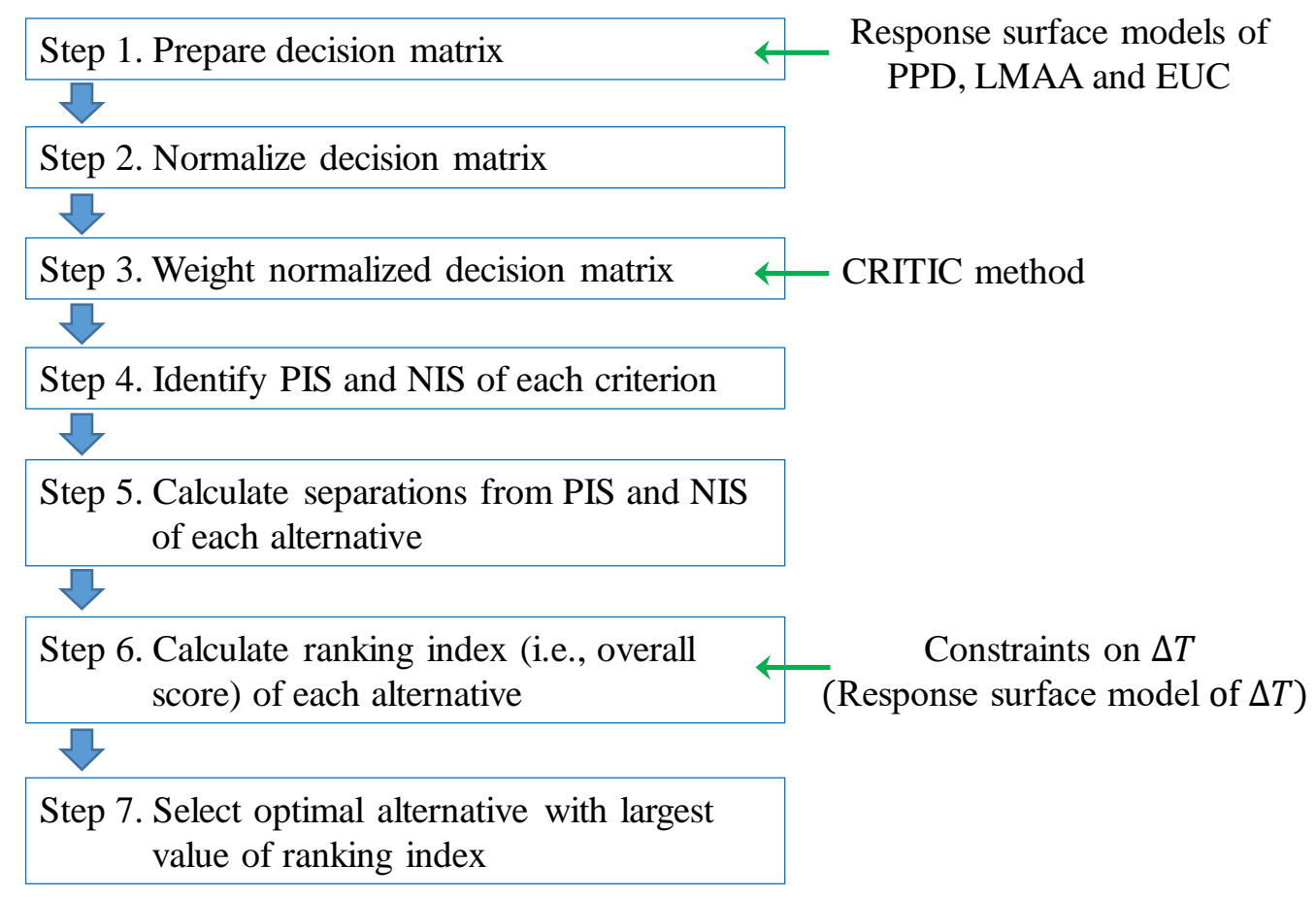

Note: PIS and NIS denote the positive ideal solution and the negative ideal solution, respectively.

Fig.5. Flowchart of multi-criteria performance optimization using TOPSIS based on response surface models. 
Volume 239, 1 April 2019, Pages 969-98

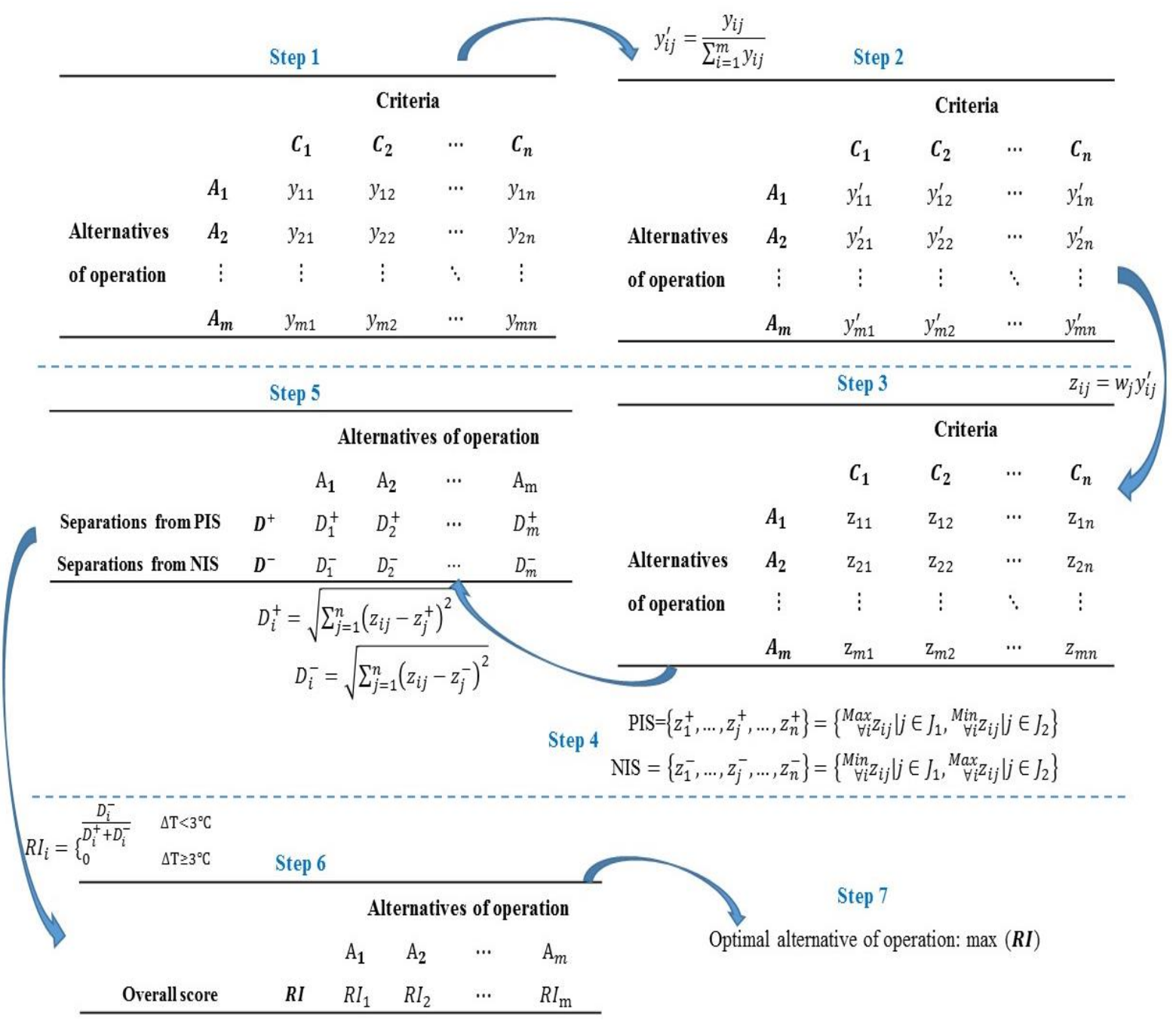

Fig.6. Transformations of decision matrix of TOPSIS optimization.

In Step 3, the weight factors allocated to the criteria of the ventilation performance are typically objectively determined by Shannon's entropy theory, in a manner that the weight factors should reflect the amount of information contained by the corresponding criteria [24]. Shannon's entropy theory calculates the amount of information from the contrast intensity of the criterion [49]. The criterion with lower contrast intensity means that all alternatives of operation have a more similar performance of that criterion; therefore, this specific criterion offers less information and is allocated a smaller weight factor. However, the contained information should also reflect the conflictions among the criteria, according to the notion that the incorporation of several interdependent criteria could yield misleading results [50]. Thus, the criteria importance through inter-criteria correlation (CRITIC) method is employed to determine the weight factors; this method calculates the information of criteria from both the contrast intensities and conflictions (Equations 11 and 12) [50, 
51]. The weight factors can also be calculated using the expected value method or can be subjectively determined by the preferences of the users, which require the participation of shareholders $[52,53]$ and are not considered in this study.

$$
\begin{gathered}
w_{j}=\frac{M_{j}}{\sum_{j=1}^{n} M_{j}} \\
M_{j}=\sigma_{j} \sum_{k=1}^{n}\left(1-r_{j k}\right)
\end{gathered}
$$

where $M_{j}$ is the amount of information contained by the $j^{\text {th }}$ criterion; $\sigma_{j}$ is the standard deviation of the $j^{\text {th }}$ criterion representing the contrast intensity; $n$ is the number of criteria; $r_{j k}$ is the Spearman rank correlation coefficient between the $j^{\text {th }}$ and $k^{t h}$ criteria representing the conflictions.

\section{Results and analyses}

\subsection{Validation of CFD simulation}

Retaining the same setup as that of the experiment, the predicted air velocities and temperatures from the CFD simulations are compared with the experimental measurements. In general, the predicted air velocities and temperatures present similar variation patterns as those of the experimental measurements; however, the discrepancies are obvious at certain measuring points (Figure 7). On the one hand, the discrepancies may be ascribed to the CFD computational errors [54]. On the other hand, the discrepancies can be attributed to the experimental errors to a certain extent. First, it is difficult to maintain the experimental boundaries steady. Second, the accuracy of the measurement of the velocity using omnidirectional thermal anemometers is relatively low for low air velocities [55]. Similar results have been reported in other studies $[12,56]$. In this study, the mean absolute differences of the air velocity and temperature between the predictions obtained via CFD simulations and the experimental measurements are $0.07 \mathrm{~m} / \mathrm{s}$ and $0.3^{\circ} \mathrm{C}$, respectively. The correlated coefficient and normalized mean square error are used to further examine the agreement between the predictions and corresponding experimental data [57]. For air velocity, the correlated coefficient and normalized mean square error are 0.72 and 0.5 , respectively. For air temperature, correlated coefficient and normalized mean 
square error are 0.70 and 0.0004 , respectively. These indicate a satisfactory agreement between the predictions and experimental data [57]. Thus, the CFD method adopted in this study is validated.
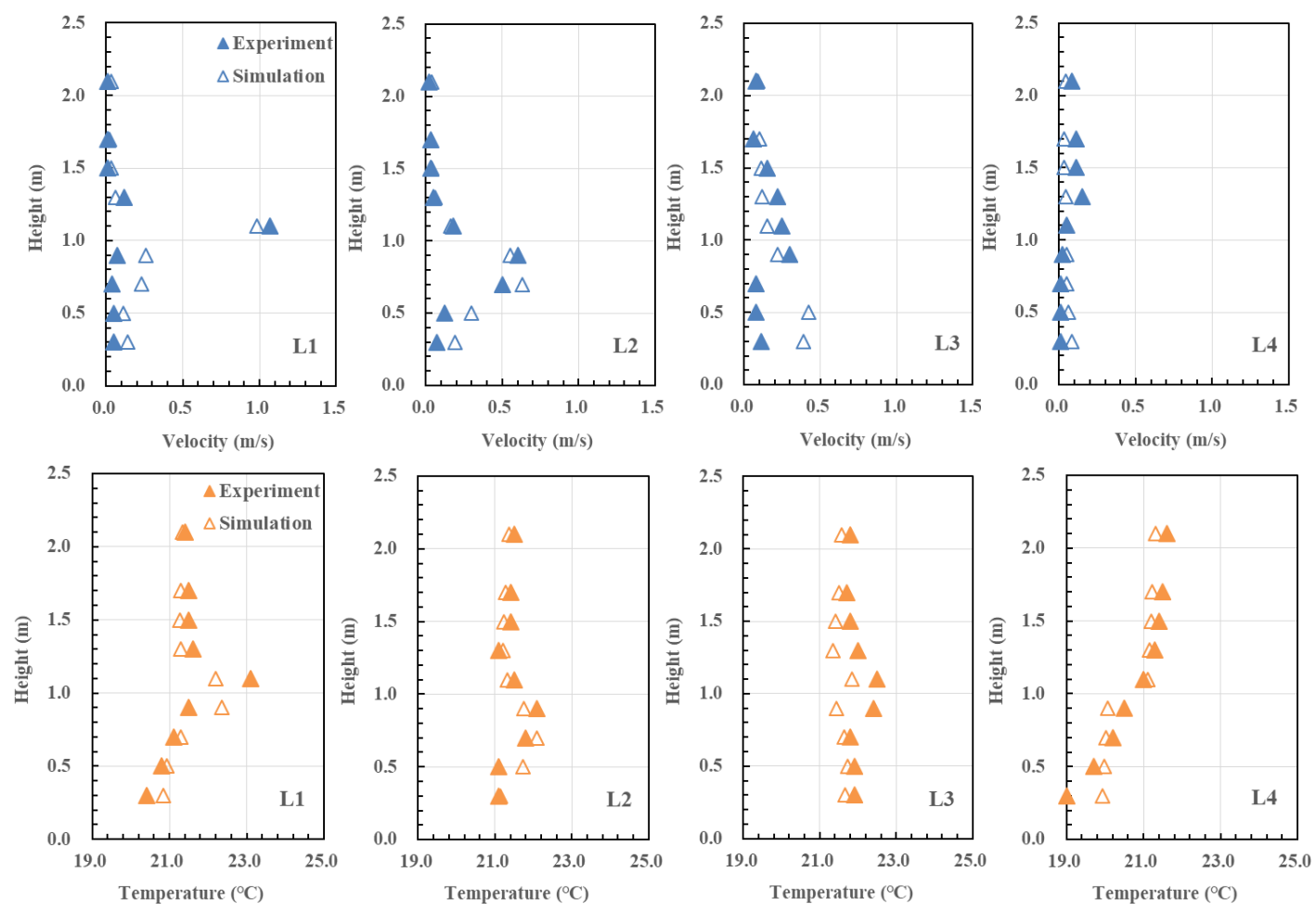

Note: L1-L4 are four sampling lines in Figure 2(a).

Fig.7. Comparisons of CFD-predicted velocities and temperatures with experimental measurements.

\subsection{Multi-criteria performance modeling}

The PMV, the vertical air temperature difference $(\Delta T)$, the LMAA, and the EUC of Cases 1 to 25 are calculated via CFD simulations and are listed in Table 1. The PMV is determined at the head level (1.1 $\mathrm{m}$ height above floor) [16, 22]. For the calculation of the PMV, the relative humidity is set to $50 \%$, the clothing level is set to 1.0 clo as the typical winter clothing level, and the activity level is set to 1.1 met [29]. The vertical air temperature difference $(\Delta \mathrm{T})$ is the air temperature difference between the head level (height of $1.1 \mathrm{~m}$ above the floor for seated occupants) and the ankle level (height of $0.1 \mathrm{~m}$ above the floor). The LMAA is determined at the breathing level (height of $1.1 \mathrm{~m}$ above the floor for seated occupants) [11]. The simulated PMV ranges from -0.75 to 0.59 , the vertical air temperature difference $(\Delta \mathrm{T})$ fluctuates from 
0.49 to $3.06^{\circ} \mathrm{C}$, the LMAA varies from 642 to $2005 \mathrm{~s}$, and the EUC ranges from 0.75 to 1.78 , indicating an indoor environment from poor to good thermal comfort and indoor air quality, with an energy efficiency from a low level to a high level. Based on the results from the CFD simulations, the response surface models of the PMV, the vertical air temperature difference $(\Delta T)$, the LMAA, and the EUC are developed (Equations 13 to 16). It is noted that the response surface model of the PPD is derived from Equations 1 and 13. These response surface models are expressed using the normalized design parameters (Equation 17) [58]. Normalization helps to remove anomalies caused by the different units and scales of the inputs [42].

$$
\begin{gathered}
P M V=-0.12 \overline{V A_{\mathrm{s}}}+0.11 \bar{V}_{\mathrm{s}}+0.16 \bar{T}_{\mathrm{s}}+0.46 \overline{T_{\mathrm{w}}}-0.08 \\
\Delta T=-0.73 \overline{V A_{\mathrm{s}}}+0.25 \bar{T}_{\mathrm{s}}-0.48{\overline{T_{\mathrm{w}}}}^{2}-0.31{\overline{V A_{\mathrm{s}}}}^{2}+1.75 \\
L M A A=140 \overline{V A_{\mathrm{s}}}-346 \bar{V}_{\mathrm{s}}+156{\overline{V A_{\mathrm{s}}}}^{2}+100 \bar{V}_{\mathrm{s}}^{2}+887 \\
E U C=-0.20 \overline{V A_{\mathrm{s}}}+0.05 \bar{V}_{\mathrm{s}}-0.04 \bar{T}_{\mathrm{s}}+0.07{\overline{T_{\mathrm{w}}}}^{2}-0.26{\overline{V A_{\mathrm{s}}}}^{2}+1.24,
\end{gathered}
$$

where $\overline{V A_{\mathrm{S}}}$ is the normalized supply vane angle; $\bar{V}_{\mathrm{S}}$ is the normalized supply airflow rate; $\bar{T}_{\mathrm{s}}$ is the normalized supply air temperature; and $\overline{T_{\mathrm{w}}}$ is the normalized inside surface temperature of the exterior envelope.

$$
\bar{x}=\frac{2\left(x-x_{\min }\right)}{x_{\max }-x_{\min }}-1
$$

where $\bar{x}$ is the normalized value of the design parameter; $x$ is the original value of the design parameter; $x_{\min }$ and $x_{\max }$ are the minimal and maximal original values of the design parameter, respectively.

The ANOVA test reveals that these response surface models have a $p$ value of less than 0.0001 , indicating that these models are statistically significant (Table 2). The coefficient of determination $\left(R^{2}\right)$ of the PMV is 0.96 , with a predicted $R^{2}$ of 0.94 , which is in reasonable agreement with the adjusted $R^{2}$ of 0.95 . The $R^{2}$ of the vertical air temperature difference $(\Delta T)$ is 0.82 , with the predicted $R^{2}$ of 0.72 being in reasonable agreement with the adjusted $R^{2}$ of 0.79 . The $R^{2}$ of the LMAA is 0.99, with the predicted $R^{2}$ of 0.98 being in reasonable agreement with the adjusted $R^{2}$ of 0.98 . The $R^{2}$ of the EUC is 0.95 , with the predicted $R^{2}$ of 0.90 being in reasonable agreement with the adjusted $R^{2}$ of 0.93 . The adjusted $R^{2}$ is the $R^{2}$ adjusted by the total number of the design points and model terms. The predicted $R^{2}$ is calculated via Equation 18 [26]. 


$$
\text { Predicted } R^{2}=1-\frac{P R E S S}{S S_{\text {total }}}
$$

where PRESS is calculated by systematically removing each observation from the dataset, thus formulating a new model using the remaining dataset and calculating the variance between predicted values via the newly established models and the removed observations; $S S_{\text {total }}$ is the total variance between the model predictions and observations.

Table 2. Statistical analyses of the developed response surface models.

\begin{tabular}{|c|c|c|c|c|}
\hline \multirow{2}{*}{} & \multicolumn{2}{|c|}{ Thermal comfort } & Air quality & Energy efficiency \\
\cline { 2 - 5 } & PMV & $\Delta T$ & LMAA & EUC \\
\hline$R^{2}$ & $<0.0001$ & $<0.0001$ & $<0.0001$ & $<0.0001$ \\
\hline Adjusted $R^{2}$ & 0.9533 & 0.7870 & 0.9821 & 0.9449 \\
\hline Predicted $R^{2}$ & 0.9394 & 0.7191 & 0.9759 & 0.8988 \\
\hline MAE & 0.06 & $0.27^{\circ} \mathrm{C}$ & $39 \mathrm{~s}$ & 0.05 \\
\hline SD & 0.04 & $0.14^{\circ} \mathrm{C}$ & $72 \mathrm{~s}$ & 0.09 \\
\hline
\end{tabular}

Note: MAE is the mean absolute error (Equation 19); SD is the standard deviation (Equation 20).

Figure 8 presents the comparisons between the predictions obtained via the response surface models and those via the CFD simulations for Cases 1-25. The mean absolute error (MAE) of the predictions of the PMV obtained from the response surface model (Equation 13) is 0.06 with a standard deviation of 0.04 (Equations 19 and 20 [42]) (Table 2). The MAE of the predictions of the vertical air temperature difference $(\Delta T)$ obtained from the response surface model (Equation 14) is $0.27^{\circ} \mathrm{C}$ with a standard deviation of $0.14^{\circ} \mathrm{C}$. The MAE of the predictions of the LMAA from the response surface model (Equation 15) is $39 \mathrm{~s}$ with a standard deviation of $72 \mathrm{~s}$. The MAE of predictions of the EUC from the response surface model (Equation 16) is 0.05 with a standard deviation of 0.09 . Thus, these response surface models are statistically reliable $[26,28]$.

$$
M A E=\frac{\sum_{i=1}^{N}\left|\operatorname{sim}_{\mathrm{i}}-\operatorname{pre}_{\mathrm{i}}\right|}{N}
$$




$$
S D=\sqrt{\frac{\sum_{i=1}^{N}\left(\left|\operatorname{sim}_{\mathrm{i}}-\operatorname{pre}_{\mathrm{i}}\right|-\frac{1}{N} \sum_{j=1}^{N}\left|\operatorname{sim}_{\mathrm{i}}-\operatorname{pre}_{\mathrm{i}}\right|\right)^{2}}{N-1}}
$$

where $M A E$ is the mean absolute error; $\left|\operatorname{sim}_{\mathrm{i}}-\operatorname{pre}_{\mathrm{i}}\right|$ is the absolute deviation between the CFD simulation $\left(\operatorname{sim}_{\mathrm{i}}\right)$ and the prediction of the response surface model (pre $\left._{\mathrm{i}}\right) ; i$ is Case $i ; N$ is the number of cases; SD is the standard deviation of the absolute deviations between the CFD simulations and the predictions obtained from the response surface model.
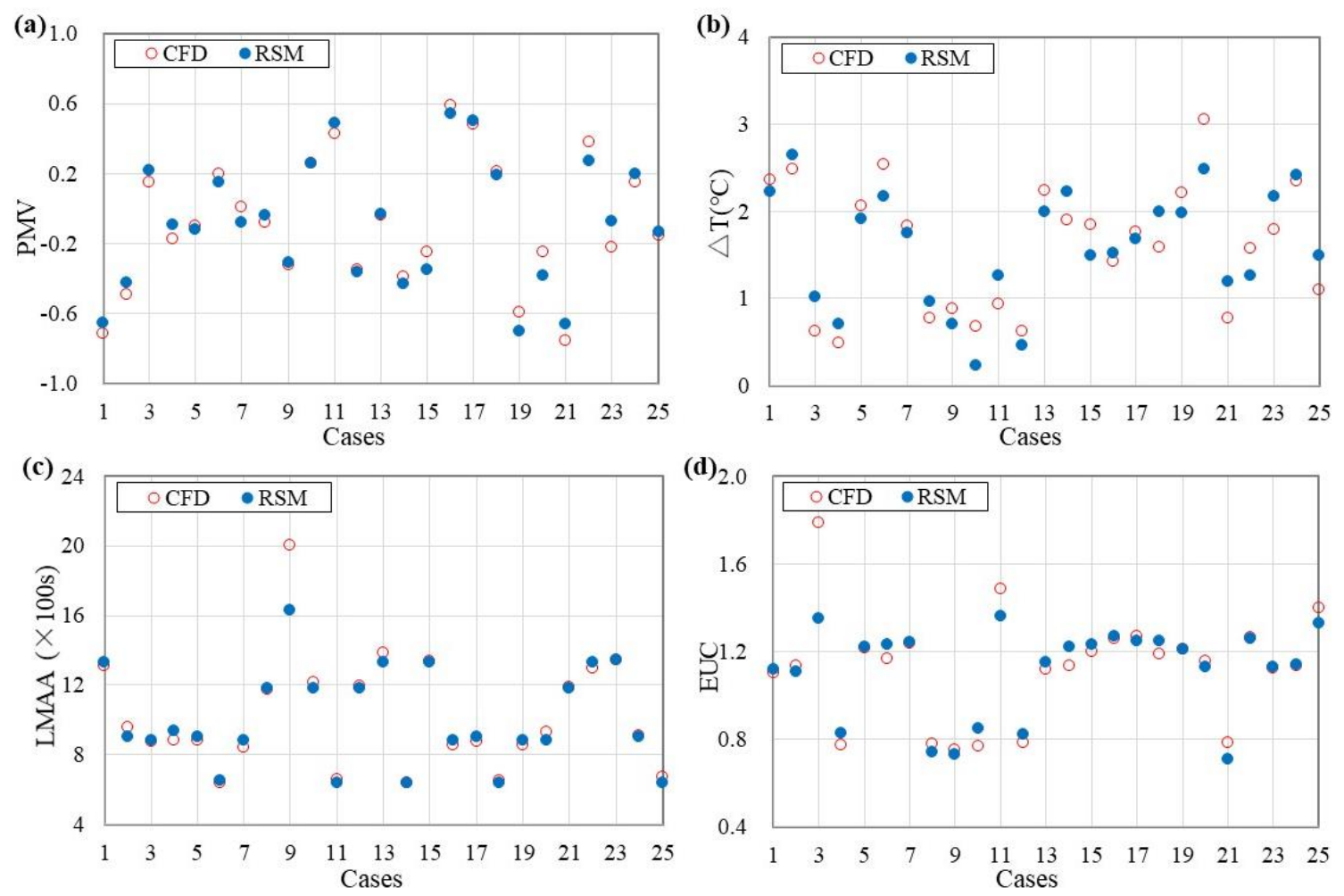

Fig.8. Comparisons between ventilation performance from response surface models (RSM) and CFD simulations: (a) Predicted Mean Vote (PMV); (b) vertical air temperature difference $(\Delta T)$; (c) local mean age of air (LMAA); and (d) energy utilization coefficient (EUC).

\subsection{Multi-criteria performance optimization and analyses}

The considered alternatives of operation are 21 different supply vane angles from $0^{\circ}$ to $70^{\circ}$ with equal intervals, 21 different supply airflow rates from 0.02 to $0.04 \mathrm{~m}^{3} / \mathrm{s}$ with equal intervals, and 21 different supply air temperatures from 24 to $28^{\circ} \mathrm{C}$ with equal intervals. Thus, there are 9,261 alternatives of operation. The weight factors for 
Volume 239, 1 April 2019, Pages 969-98

the PPD, the LMAA, and the EUC are 0.36, 0.38, and 0.26, respectively. As an example, Figure 9 shows the overall scores of the 9,261 alternatives of operation from the largest to the smallest at the inside surface temperature of the exterior envelope of $10^{\circ} \mathrm{C}$. It is observed that the overall scores can vary substantially from zero to approximately one. The overall score is zero because inappropriate operation results in a vertical air temperature difference $(\Delta T) \geqslant 3^{\circ} \mathrm{C}$ (Section 2.5). The substantial variations of the overall scores indicate that the selected alternative of operation needs to be properly determined to avoid poor ventilation performance (i.e., small overall score).

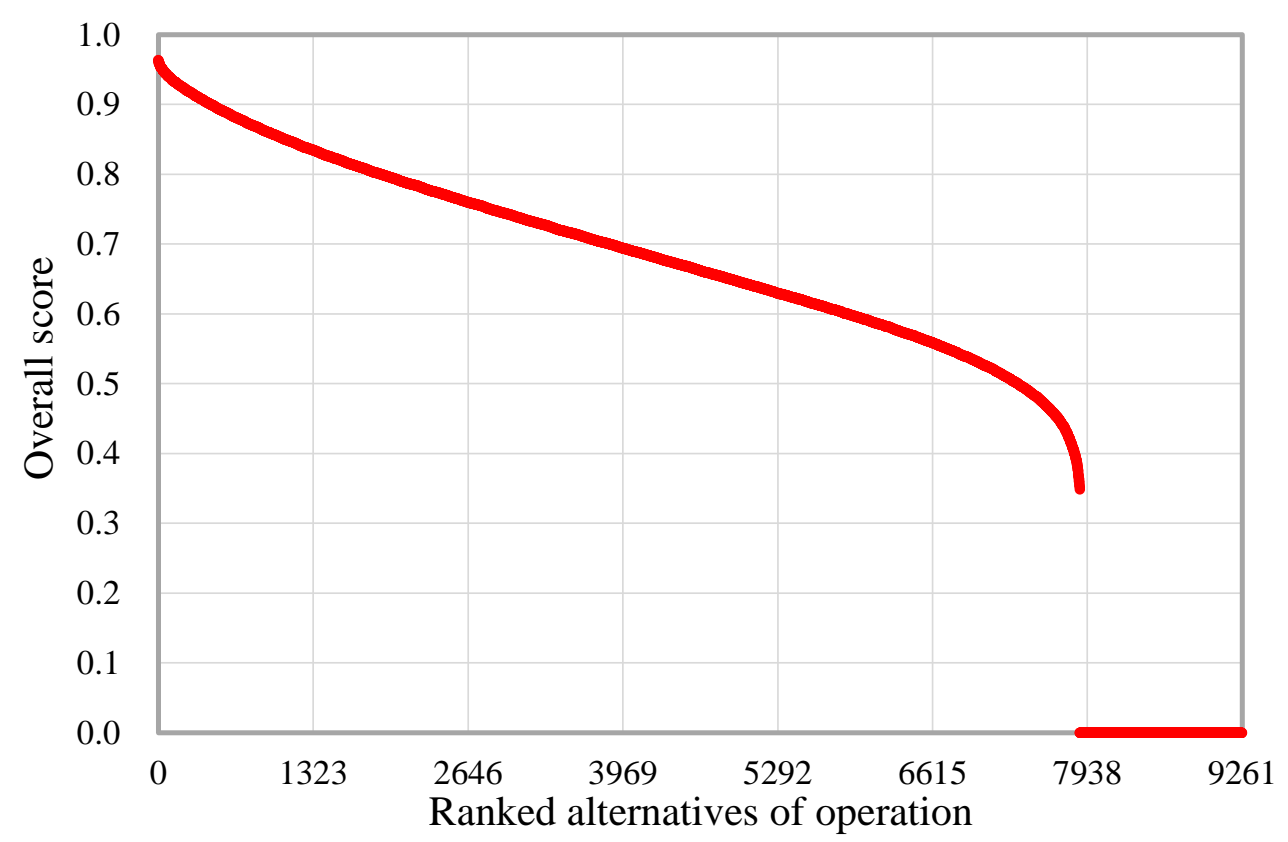

Fig.9. Variations of overall scores of all alternatives of operation.

Twenty-one different inside surface temperatures of the exterior envelope from 10 to $17^{\circ} \mathrm{C}$ with equal intervals are designed for the study of the effects of outdoor weather conditions [41, 42]. For each inside surface temperature of the exterior envelope, the RSM-based TOPSIS optimization sorts the corresponding optimal operation. To quantify the performance improvement achieved via the RSM-based TOPSIS optimization, a benchmark is defined. The benchmark is the operation with a medium value of each ventilation parameter to achieve reasonably good ventilation performance because no other optimization on stratum ventilation for heating exists: a supply vane angle of $35^{\circ}$, a supply airflow rate of $0.03 \mathrm{~m}^{3} / \mathrm{s}$, and a supply air temperature of $26^{\circ} \mathrm{C}$ [19]. Figure 10 shows that in general, the ventilation 
performance of the benchmark is reasonably good with a PPD of no greater than $10 \%$, an LMAA of $887 \mathrm{~s}$ and an EUC ranging from 1.17 to 1.31 [30]. For both the RSM-based TOPSIS optimization and the benchmark, the vertical air temperature difference $(\Delta T)$ is less than $3^{\circ} \mathrm{C}$ (Section 2.5 and Equation 14) [30]. This is mainly facilitated from the reasonable airflow pattern of stratum ventilation, where the warm air is directly supplied to the occupied zone. Figure 10 shows that the RSM-based TOPSIS optimization robustly achieves good ventilation performance when the inside surface temperature of the exterior envelope varies from 10 to $17^{\circ} \mathrm{C}$, with the PPD within the range of 5.0\%-6.7\%, the LMAA within the range of 610-710 s, and the EUC within the range of 1.22-1.40. Compared with the benchmark, the RSM-based TOPSIS optimization reduces the PPD and the LMAA up to $46.7 \%$ and $31.2 \%$, respectively, and by $16.3 \%$ and $29.5 \%$ on average, respectively. Moreover, the EUC is increased up to $10.3 \%$ and, on average, by $7.0 \%$. The significant ventilation performance improvements of the RSM-based TOPSIS optimization indicate that it is beneficial and necessary to perform such an optimization.

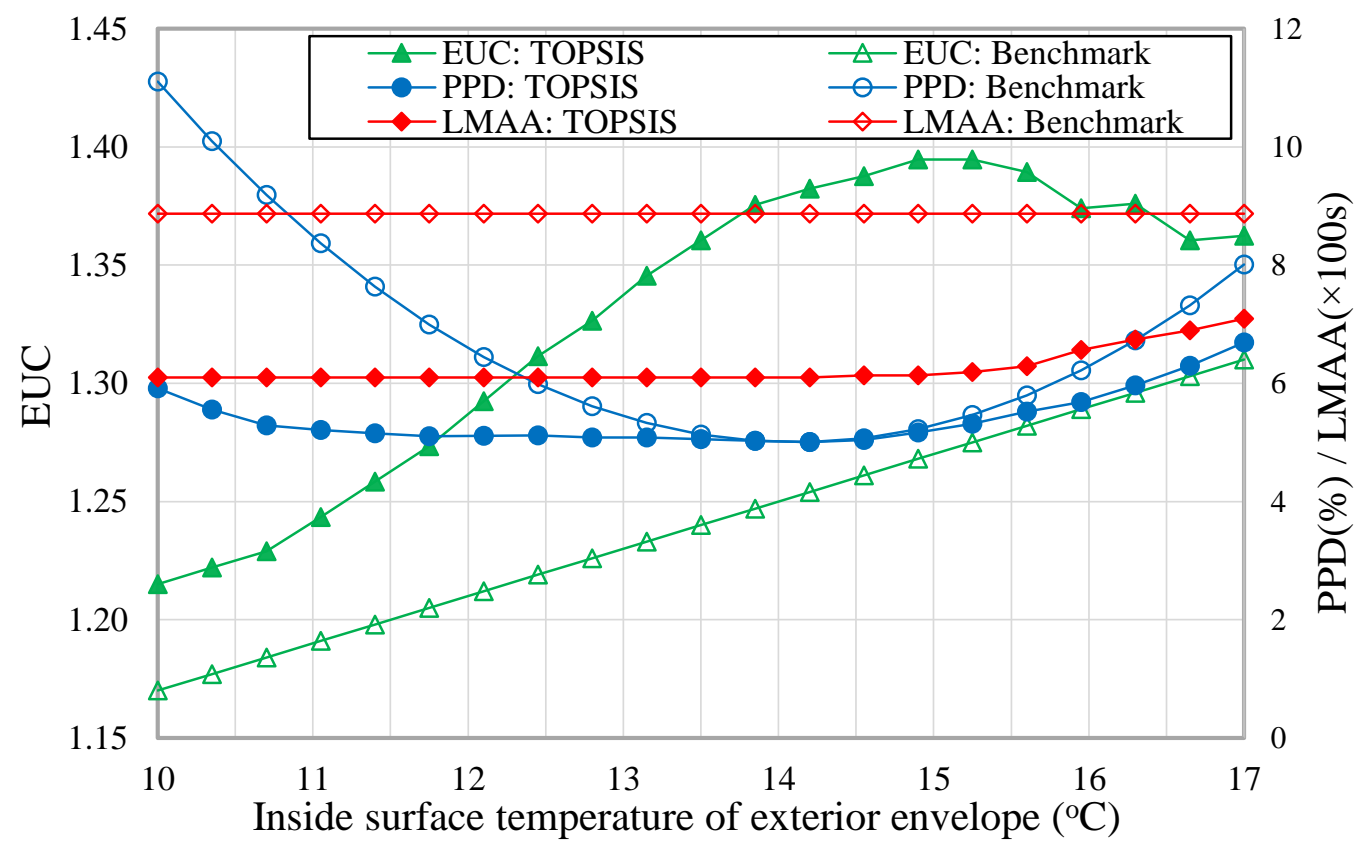

Fig.10. Comparisons of ventilation performance between RSM-based TOPSIS optimization and benchmark.

Figure 11 shows the variations in the optimal operation with inside surface temperatures of the exterior envelope. The optimal values of the ventilation parameters are normalized to be within -1 and 1 for the purpose of 
Volume 239, 1 April 2019, Pages 969-98

comparison(Equation 17). It is seen that the optimal operation needs to be updated dynamically to respond to the variations in the outdoor weather conditions. At a higher inside surface temperature of the exterior envelope, the optimal supply vane angle tends to increase, whereas the optimal supply airflow rate and the optimal supply air temperature tend to decrease. The optimal supply air temperature varies the most significantly, covering the entire range (from -1 to 1 ). The variations in the optimal supply vane angle are less significant, covering $30 \%$ of the entire range (i.e., from -0.5 to 0.1 ). The variations in the optimal supply airflow rate are the least significant, covering only $15 \%$ of the entire range (i.e., from 0.7 to 1 ). Moreover, the optimal supply air temperature requires the most frequent updates with 10 different values (i.e., $-1,-0.8,-0.6,-0.3,-0.1,0.2,0.5,0.7,0.9$, and 1 ), followed by the optimal supply vane angle with seven different values (i.e., $-0.5,-0.4,-0.3,-0.2,-0.1,0$, and 0.1 ), and then the optimal supply airflow rate with four different values (i.e., 0.7, 0.8, 0.9, and 1). These indicate that the optimal operation is the most sensitive to the supply air temperature, followed by the supply vane angle, and then, by the supply airflow rate. Thus, in practice, the supply air temperature needs to be most carefully monitored and adjusted according to the variations in the outdoor weather conditions.

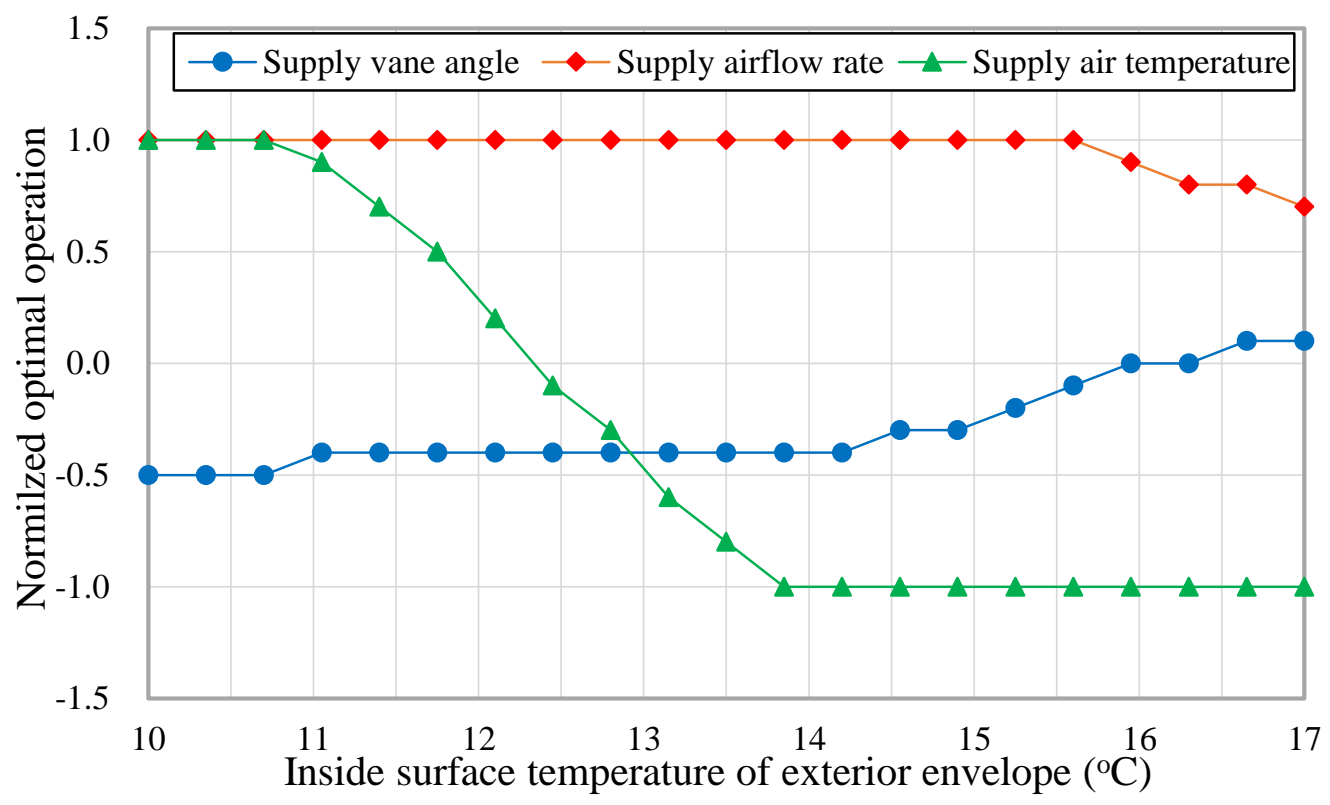

Note: Values of optimal ventilation parameters are normalized within -1 and 1 (Equation 17).

Fig.11. Optimal operations of supply vane angle, supply airflow rate and supply air temperature for different inside surface temperatures of exterior envelope. 
Volume 239, 1 April 2019, Pages 969-98

To further confirm the accuracy of the ventilation performance from the RSM-based TOPSIS optimization, the optimized ventilation performance (i.e., the PPD, the LMAA, and the EUC) of the 21 optimal operations (Figure 11) are re-calculated via CFD simulations. Figure 12 shows that the PPD, the LMAA, and the EUC of the 21 optimal operations from the RSM-based TOPSIS optimization reasonably agree with those from the CFD simulations, with MAE of $0.27 \%, 22 \mathrm{~s}$, and 0.11 , respectively (Equation 19), and a standard deviation of $0.23 \%, 13 \mathrm{~s}$, and 0.06 , respectively (Equation 20). Thus, the RSM-based TOPSIS optimization is credible.
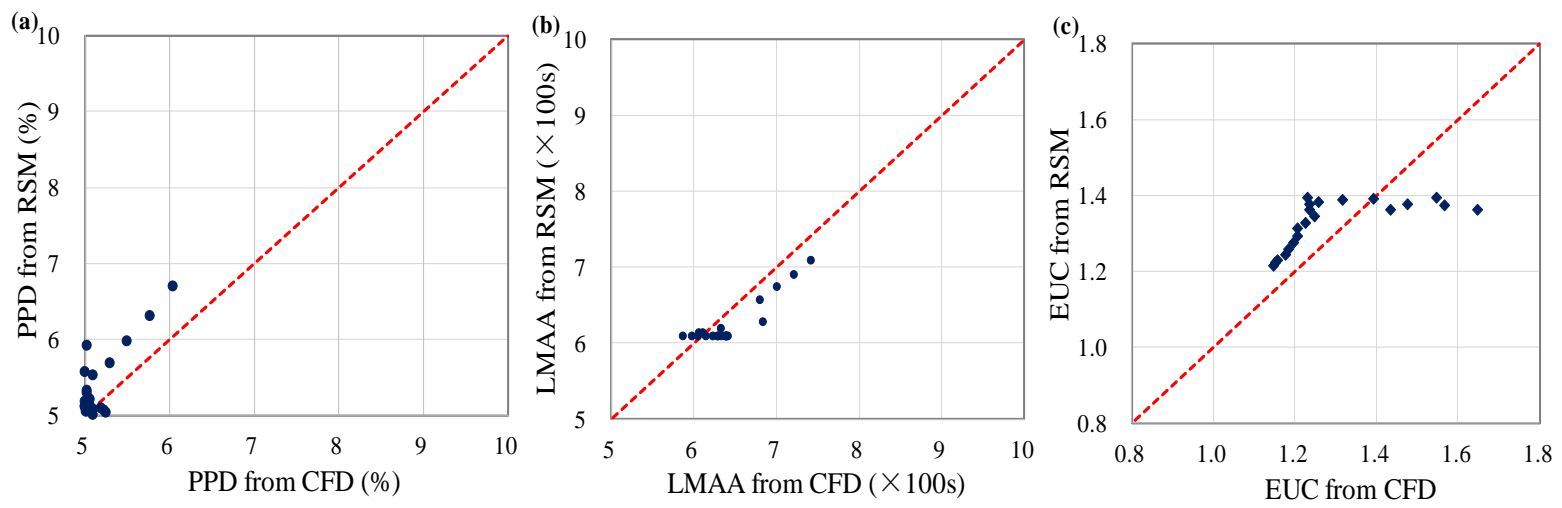

Fig.12. Comparison between ventilation performance of optimal operations from RSM-based TOPSIS optimization and those from CFD simulations: (a) Predicted Percentage of Dissatisfied (PPD); (b) local mean age of air (LMAA); and (c) energy utilization coefficient (EUC).

\section{Discussion}

This study shows that the optimal operation is more sensitive to the supply air temperature than the supply airflow rate. This implies that when only one of these two parameters is adjustable, the system with a variable supply air temperature (i.e., the constant-air-volume system) might outperform the system with a variable supply airflow rate (i.e., the variable-air-volume system). The ventilation performance of these two systems is further compared regarding the overall score of the optimal operation (Equation 10) (Figure 13). The supply airflow rate of the constant-air-volume system is set to $0.04 \mathrm{~m}^{3} / \mathrm{s}$, because for most outdoor weather conditions the optimal supply airflow rate is $0.04 \mathrm{~m}^{3} / \mathrm{s}$ (Figure 11). The supply air temperature of the variable-air-volume system is set to $24^{\circ} \mathrm{C}$, because for most outdoor weather conditions the optimal supply air temperature is $24^{\circ} \mathrm{C}$ (Figure 11). 
Volume 239, 1 April 2019, Pages 969-98

Figure 13 shows that when the inside surface temperature of the exterior envelope is lower than $13.5^{\circ} \mathrm{C}$, the overall score of the optimal operation of the constant-air-volume system is significantly higher than that of the variable-air-volume system. The overall score improvement by the constant-air-volume system increases with the decrease in the inside surface temperature of the exterior envelope, and could reach as high as $18.3 \%$ at the inside surface temperature of the exterior envelope of $10^{\circ} \mathrm{C}$. This is because the lower the inside surface temperature of the exterior envelope is, the larger the difference between the supply air temperature setting (i.e., $24^{\circ} \mathrm{C}$ ) of the variable-air-volume system and the optimal supply air temperature is (Figure 11), which results in the poor overall score of the variable-air-volume system.

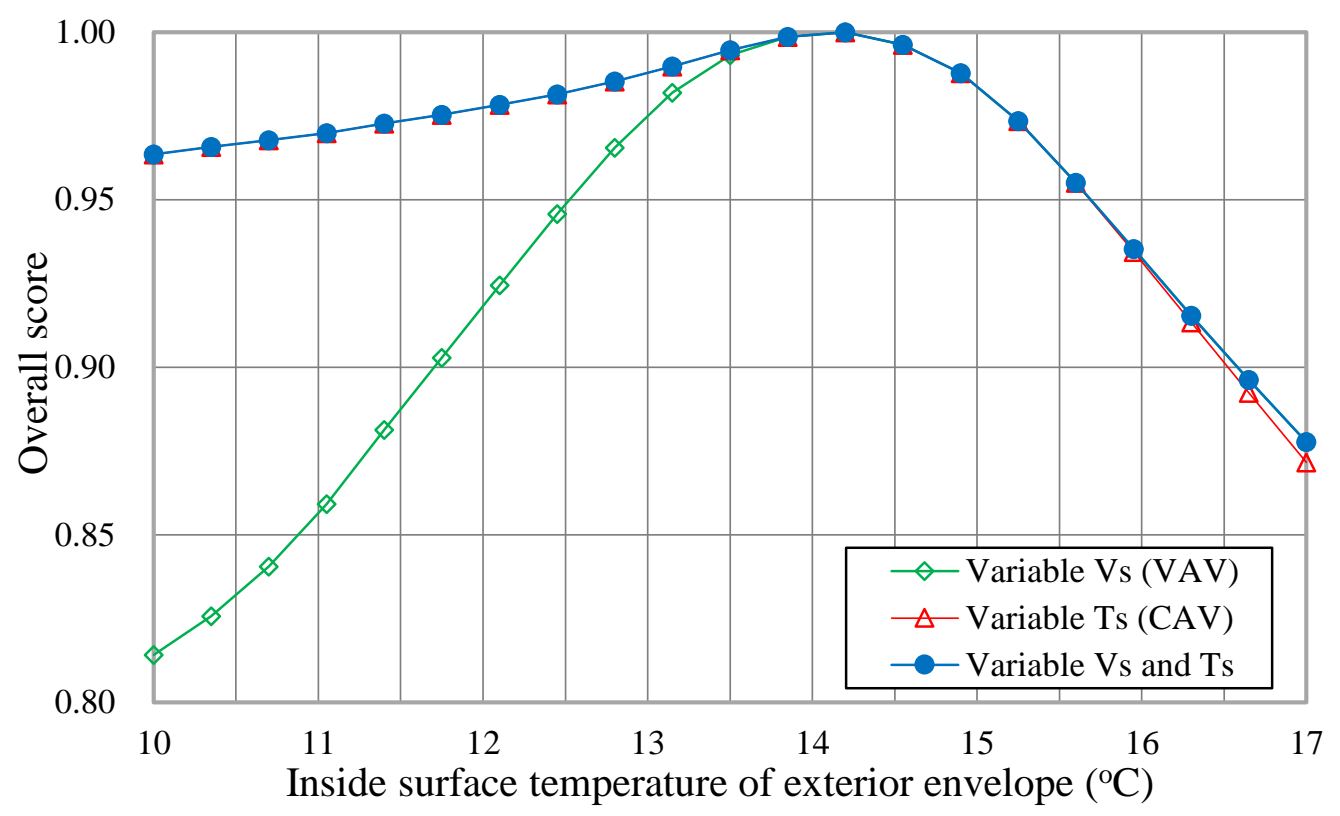

Note: Overall score denotes

Fig.13. Comparison of overall scores of the optimal operations among the variable-air-volume system (VAV), the constant-air-volume system (CAV), and the system with the variable supply airflow rate and the supply air temperature.

However, when the inside surface temperature of the exterior envelope is higher than $16^{\circ} \mathrm{C}$, the overall score of the optimal operation of the constant-air-volume system becomes slightly less than that of the variable-air-volume system, with a deviation of less than $0.7 \%$. This is because with an inside surface temperature of the exterior envelope of more than $16^{\circ} \mathrm{C}$, the setting supply airflow rate (i.e., $0.04 \mathrm{~m}^{3} / \mathrm{s}$ ) of the constant-air-volume system slightly deviates from the optimal supply airflow rate 
(Figure 11). Averagely, the constant-air-volume system improves the overall score by $6.2 \%$ compared with that of the variable-air-volume system with the inside surface temperature of the exterior envelope from 10 to $17^{\circ} \mathrm{C}$. Thus, the constant-air-volume system is better preferred. Moreover, the overall score of the optimal operation of the constant-air-volume system is close to that of the system with both variable supply airflow rate and supply air temperature, with a deviation of less than $0.7 \%$. Thus, compared with the system with both variable supply airflow rate and supply air temperature, the constant-air-volume system is recommended owing to the comparable ventilation performance and the simplicity.

This study demonstrates the efficiency of the RSM-based TOPSIS optimization. On the one hand, the optimal operations are sorted, which largely improve the ventilation performance (Section 3.3). On the other hand, the RSM-based TOPSIS optimization is computationally efficient. The RSM-based TOPSIS optimization only requires CFD simulations of 25 cases determined by the Box-Behnken design. If without the response surface models, CFD simulations are required for a total of 194,481 cases $(9261 \times 21=194,481)$. The CFD simulations of one case require approximately $7 \mathrm{~h}$ using a computer with an Intel Core i7-4790 CPU. The computational cost for the CFD simulations of the 194,481 cases is too excessive to conduct such optimizations in practice. The proposed RSM-based TOPSIS optimization provides an efficient method for the improvement of the operation performance of stratum ventilation for heating. Moreover, because the RSM has been confirmed to be applicable to natural ventilation, displacement ventilation, impinging jet ventilation, etc. [27, 28], the proposed RSM-based TOPSIS optimization is promising for the aforementioned ventilation methods.

\section{Conclusions}

In this study, an efficient method for the improvement of the operation performance of stratum ventilation for heating is presented. The operations are optimized with a multi-criteria decision-making technology, namely TOPSIS. The TOPSIS optimization is based on the response surface models (RSM) of the PMV/PPD, the vertical air temperature difference $(\Delta T)$, the LMAA, and the EUC to reduce the 
computational cost. The response surface models reasonably agree with the experimentally validated CFD simulations. The RSM-based TOPSIS optimization aims to minimize the PPD and the LMAA, as well to maximize the EUC, while limiting the vertical air temperature difference $(\Delta T)$ to be less than $3^{\circ} \mathrm{C}$. The main findings were the following:

(1) The ventilation performance improvements through the optimization are significant. An average reduction in the PPD and the LMAA by $16.3 \%$ and $29.5 \%$, respectively, and an average increase in the EUC by $7.0 \%$ are achieved.

(2) The optimal operation is most sensitive to the supply air temperature, followed by the supply vane angle, and then the supply airflow rate. With the ability to modulate the supply air temperature, the constant-air-volume system outperforms the variable-air-volume system by $6.2 \%$ on average and is recommended for stratum ventilation for heating.

(3) The RSM largely improves the computational efficiency of the TOPSIS optimization by reducing the required number of the CFD simulations from 194,481 to 25 . With the greatly improved computational efficiency, the proposed RSM-based TOPSIS optimization is feasible and promising for the optimization of the indoor thermal environment in practice. Moreover, the proposed RSM-based TOPSIS optimization has the potential to be applicable to other air distributions (e.g., displacement ventilation).

\section{Acknowledgment}

The work presented in this paper is financially supported by National Natural Science Foundation of China (Grant No. 51878585, and Grant No. 51561135002). We also thank Ruiduan Han for his work in the experiments.

\section{References}

[1] Liu Z, Xu W, Zhai X, Qian C, Chen X. 2017. Feasibility and performance study of the hybrid ground-source heat pump system for one office building in Chinese heating dominated areas. Renewable Energy, 101, 1131-1140.

[2] Huang P, Huang G, Sun Y. 2018. Uncertainty-based life-cycle analysis of 
near-zero energy buildings for performance improvements. Applied Energy, 213, 486-498.

[3] Melikov AK. 2016. Advanced air distribution: Improving health and comfort while reducing energy use. Indoor Air, 26(1), 112-124.

[4] Cheng Y, Yang B, Lin Z, Yang J, Du Z. 2018. Cooling load calculation methods in spaces with stratified air: A brief review and numerical investigation. Energy and Buildings, 165, 47-55.

[5] Lin Z, Chow TT, Tsang CF, Fong KF, Chan LS. 2009. Stratum ventilation - a potential solution to elevated indoor temperatures. Building and Environment, 44(11), 2256-2269.

[6] Zhang S, Cheng Y, Oladokun MO, Huan C, Lin Z. 2019. Heat removal efficiency of stratum ventilation for air-side modulation. Applied Energy, Accept.

[7] Lin Z, Lee CK, Fong S, Chow TT, Yao T, Chan ALS. 2011. Comparison of annual energy performances with different ventilation methods for cooling. Energy and Buildings, 43(1), 130-136.

[8] Fong KF, Lee CK, Lin Z. 2019. Investigation on effect of indoor air distribution strategy on solar air-conditioning systems. Renewable Energy, 131, 413-421.

[9] Zhang S, Cheng Y. 2017. Performance improvement of an ejector cooling system with thermal pumping effect (ECSTPE) by doubling evacuation chambers in parallel. Applied Energy, 187, 675-688.

[10]Cheng Y, Lin Z, Fong AM. 2015. Effects of temperature and supply airflow rate on thermal comfort in a stratum-ventilated room. Building and Environment, 92, 269-277.

[11]Huan C, Wang FH, Lin Z, Wu XZ, Ma ZJ, Wang ZH, Zhang LH. 2016. An experimental investigation into stratum ventilation for the cooling of an office with asymmetrically distributed heat gains. Building and Environment, 110, 76-88.

[12] Shao X, Wang K, Li X, Lin Z. 2018. Potential of stratum ventilation to satisfy differentiated comfort requirements in multi-occupied zones. Building and Environment, 143, 329-338. 


\section{Applied Energy \\ Volume 239, 1 April 2019, Pages 969-98}

[13]Zhang S, Cheng Y, Oladokun MO, Lin Z. 2019. Subzone control method of stratum ventilation for thermal comfort improvement. Building and Environment, $149,39-47$.

[14]Cheng Y, Zhang S, Huan C, Oladokun MO, Lin Z. 2019. Optimization on fresh outdoor air ratio of air conditioning system with stratum ventilation for both targeted indoor air quality and maximal energy saving. Building and Environment, $147,11-22$.

[15]Zhang S, Cheng Y, Fang Z, Huan C, Lin Z. 2017. Optimization of room air temperature in stratum-ventilated rooms for both thermal comfort and energy saving. Applied Energy, 204, 420-431.

[16]Zhang S, Cheng Y, Fang Z, Lin Z. 2018. Dynamic control of room air temperature for stratum ventilation based on heat removal efficiency: Method and experimental validations. Building and Environment, 140, 107-118.

[17]Zhang S, Cheng Y, Huan C, Lin Z. 2018. Heat removal efficiency based multi-node model for both stratum ventilation and displacement ventilation. Building and Environment, 143, 24-35.

[18]Zhang S, Cheng Y, Huan C, Lin Z. 2019. Equivalent room air temperature based cooling load estimation method for stratum ventilation and displacement ventilation. Building and Environment, 148, 67-81.

[19]Zhang S, Lin Z, Ai Z, Wang F, Cheng Y, Huan C. 2019. Effects of operation parameters on performances of stratum ventilation for heating mode. Building and Environment, 148, 55-66.

[20]Fisk WJ, Faulkner D, Sullivan D, Bauman F. 1997. Air change effectiveness and pollutant removal efficiency during adverse mixing conditions. Indoor Air, 7, $55-63$.

[21]Cheng Y, Lin Z. 2015. Experimental study of airflow characteristics of stratum ventilation in a multi-occupant room with comparison to mixing ventilation and displacement ventilation. Indoor Air, 25, 662-671.

[22]Cheng Y, Fong ML, Yao T, Lin Z, Fong KF. 2014. Uniformity of stratum ventilated thermal environment and thermal sensation. Indoor Air, 24(5), 
$521-532$.

[23]Behzadian M, Otaghsara SK, Yazdani M, Ignatius J. 2012. A state-of the-art survey of TOPSIS applications. Expert Systems with Applications, 39(17), 13051-13069.

[24]Mao N, Song M, Deng S. 2016. Application of TOPSIS method in evaluating the effects of supply vane angle of a task/ambient air conditioning system on energy utilization and thermal comfort. Applied Energy, 180, 536-545.

[25]Kuo T. 2017. A modified TOPSIS with a different ranking index. European Journal of Operational Research, 260(1), 152-160.

[26] Shen X, Zhang G, Bjerg B. 2013. Assessments of experimental designs in response surface modelling process: Estimating ventilation rate in naturally ventilated livestock buildings. Energy and Buildings, 62, 570-580.

[27]Ng KC, Kadirgama K, Ng EYK. 2008. Response surface models for CFD predictions of air diffusion performance index in a displacement ventilated office. Energy and Buildings, 40(5), 774-781.

[28]Chen H, Moshfegh B, Cehlin M. 2013. Computational investigation on the factors influencing thermal comfort for impinging jet ventilation. Building and Environment, 66, 29-41.

[29]ASHRAE. 2017. Thermal environmental conditions for human occupancy, ASHRAE Standard 55- 2013. American Society of Heating, Refrigerating and Air-conditioning Engineers, Atlanta, Georgia.

[30]ISO. 7730: 2005. Ergonomics of the thermal environment-Analytical determination and interpretation of thermal comfort using calculation of the PMV and PPD indices and local thermal comfort criteria.

[31] Awbi HB. 2007. Ventilation systems: Design and performance. Taylor \& Francis.

[32] Yuan X, Chen Q, Glicksman LR. 1999. Measurements and computations of room air flow with displacement ventilation. ASHRAE Transactions, 105(1), 340-352.

[33] Shahzad S, Calautit JK, Aquino AI, Nasir DS, Hughes BR. 2017. A user-controlled thermal chair for an open plan workplace: CFD and field studies 
of thermal comfort performance. Applied Energy, 207, 283-293.

[34]Chen Q. 2009. Ventilation performance prediction for buildings: a method overview and recent publications. Building and Environment, 44(4), 848-858.

[35]Chen Q, Srebric J. 2002. A procedure for verification, validation and reporting of indoor environment CFD analyses. HVAC\&R Research, 8(2), 201-216.

[36] Airpak 3.0 User's Guide, Fluent Inc., Lebanon, US, 2007.

[37]Fluent 6.3 User’s Guide, Fluent Inc., Lebanon, US, 2006.

[38]Cheng Y, Lin Z. 2015. Technical Feasibility of a stratum-ventilated room for multiple rows of occupants. Building and Environment, 94, 580-592.

[39]Zhang Z, Zhang W, Zhai Z, Chen Q. 2007. Evaluation of various turbulence models in predicting airflow and turbulence in enclosed environments by CFD-Part 2: comparison with experimental data from literature. HVAC\&R Research, 13(6), 871-886.

[40]Cheng Y. 2015. Experimental and numerical study of air distribution characteristics and thermal environment under stratum ventilation. Ph.D. Dissertation, City University of Hong Kong.

[41]Heiselberg P. 1994. Draught risk from cold vertical surfaces. Building and Environment, 29(3), 297-301.

[42]Zhang S, Cheng Y, Huan C, Lin Z. 2018. Modeling non-uniform thermal environment of stratum ventilation with supply and exit air conditions. Building and Environment, 144, 542-554.

[43]Li X, Li D, Yang X, Yang J. 2003. Total air age: an extension of the air age concept. Building and Environment, 38(1), 1263-1269.

[44]Almatouq A, Babatunde AO. 2018. Identifying optimized conditions for concurrent electricity production and phosphorus recovery in a mediator-less dual chamber microbial fuel cell. Applied Energy, 230, 122-134.

[45]Geyer P, Schlüter A. 2014. Automated metamodel generation for Design Space Exploration and decision-making-A novel method supporting performance-oriented building design and retrofitting. Applied Energy, 119, 
537-556.

[46]Design Expert Version 8.0.6. User's Guide. Stat-Ease Inc, USA.

[47]Zhang H, Li H, Pan H, Wang A, Souzanchi S, Xu CC, Yang S. 2018. Magnetically recyclable acidic polymeric ionic liquids decorated with hydrophobic regulators as highly efficient and stable catalysts for biodiesel production. Applied Energy, 223, 416-429.

[48]Hu ZH, Yue ZB, Yu HQ, Liu SY, Harada H, Li YY. 2012. Mechanisms of microwave irradiation pretreatment for enhancing anaerobic digestion of cattail by rumen microorganisms. Applied Energy, 93, 229-236.

[49]Shannon CE, Weaver W. 1998. The mathematical theory of communication. University of Illinois press.

[50]Diakoulaki D, Mavrotas G, Papayannakis L. 1995. Determining objective weights in multiple criteria problems: The critic method. Computers \& Operations Research, 22(7), 763-770.

[51]Wang Y, Jin C, Lu M, Lu Y. 2017. Assessing the suitability of regional human settlements environment from a different preferences perspective: A case study of Zhejiang Province, China. Habitat International, 70, 1-12.

[52]Zhang S, Huang P, Sun Y. 2016. A multi-criterion renewable energy system design optimization for net zero energy buildings under uncertainties. Energy, 94, 654-665.

[53]Ziemele J, Pakere I, Blumberga D. 2016. The future competitiveness of the non-Emissions Trading Scheme district heating systems in the Baltic States. Applied Energy, 162, 1579-1585.

[54]Gilani S, Montazeri H, Blocken B. 2016. CFD simulation of stratified indoor environment in displacement ventilation: validation and sensitivity analysis. Building and Environment, 95, 299-313.

[55]Melikov A, Popiolek Z, Silva MCG, Care I, Sefker T. 2007. Accuracy limitations for low-velocity measurements and draft assessment in rooms. HVAC\&R Research, 13(6), 971-986. 
Volume 239, 1 April 2019, Pages 969-98

[56]Zheng C, You S, Zhang H, Zheng W, Zheng X, Ye, Liu Z. 2018. Comparison of air-conditioning systems with bottom-supply and side-supply modes in a typical office room. Applied Energy, 227: 304-311.

[57]Davardoost F, Kahforoushan D. 2019. Evaluation and investigation of the effects of ventilation layout, rate, and room temperature on pollution dispersion across a laboratory indoor environment. Environment Science and Pollution Research, https://doi.org/10.1007/s11356-018-3977-8.

[58]Zhang S, Sun Y, Cheng Y, Huang P, Oladokun MO, Lin Z. 2018. Response-surface-model-based system sizing for nearly/net zero energy buildings under uncertainty. Applied Energy, 228, 1020-1031. 